\title{
ARQueOLOGÍA de LAS CUENCAS DEL PASTAZA Y MORONA. REPORTE DE ZONIFICACIÓN ECOLÓGICA ECONÓMICA
}

\author{
Lic. Arqlo. Santiago Rivas Panduro' \\ Lic. Arqla. Ada Medina Mendoza ${ }^{2}$ \\ lic. Arqlo. Julio Abanto llaque 3 \\ ING. M.Sc. Richer Ríos Zumaeta ${ }^{4}$ \\ Ing. M.Sc. Corina Caldas Carrillo 5
}

$\mathbf{E}_{1}$ artículo presenta los resultados de las investigaciones arqueológicas realizadas en las cuencas del Pastaza y Morona, en mayo de 2006, a nivel de reconocimiento arqueológico in situ, que conformaron el componente del estudio arqueológico del Proyecto de Mesozonificación Ecológica-Económica en las cuencas de los ríos Pastaza y Morona. En esta etapa de campo, se descubrieron 52 sitios arqueológicos, que sumados a otros 30 sitios más, hacen de las cuencas del Pastaza y Morona un territorio con elevado potencial arqueológico que merece mayor atención.

The article presents/displays the results of the archaeological investigations of three Peruvian archaeologists realised in the river basins of the Pastaza and Morona, in May of 2006, concerning archaeological recognition in situ, that conformed the component of the archaeological study, of the Project of Economic Ecological Mesozonification in the river basins of the rivers Pastaza and Morona. In this stage of field work, 52 archaeological sites, were discovered that added an to other 30 sites, do of the river basins of the Pastaza and Morona a potential territory with archaeological remains that deserves major attention.

Responsable del Equipo Técnico del Estudio de Diagnóstico Arqueológico de la ZEE Pastaza Morona. Universidad Nacional Mayor de San Marcos / Universidad Nacional de la Amazonía Peruana.

2 Especialista de Apoyo al Estudio de Diagnóstico Arqueológico de la ZEE Pastaza Morona. Universidad Nacional Mayor de San Marcos.

3 Especialista de Apoyo al Estudio de Diagnóstico Arqueológico de la ZEE Pastaza Morona. Universidad Nacional Mayor de San Marcos.

4 Coordinador - Responsable del Equipo Técnico de Especialistas del Proyecto de ZEE Pastaza Morona. Docente de la Facultad de Ciencias Forestales de la Universidad Nacional de la Amazonía Peruana.

$5 \quad$ Responsable del Equipo Técnico del Sistema de Información Geográfica y Teledetección de la ZEE Pastaza Morona. Universidad Nacional Federico Villarreal. 
Mapa 1. Sitios Arqueológicos del área en estudio

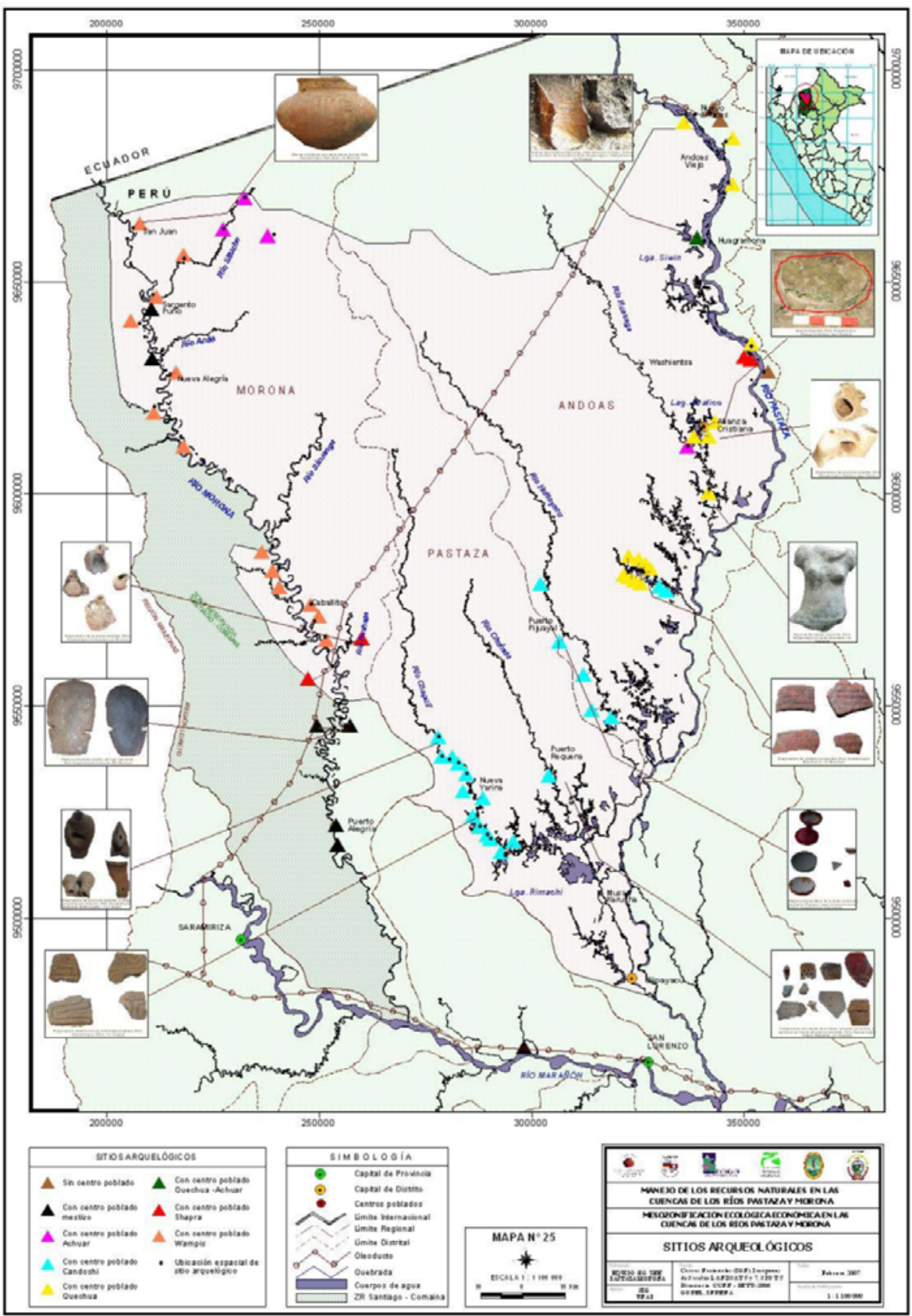




\section{Introducción}

El 2006 se llevó a cabo el Estudio de Mesozonificación Ecológica-Económica en las cuencas de los ríos Pastaza y Morona ${ }^{6}$, el mismo que incluyó en uno de sus componentes el Estudio de Diagnóstico Arqueológico (o Línea Base) ${ }^{7}$, llevado a cabo en las subcuencas del Bajo Pushaga y Bajo Anás (tributarios izquierdos del río Morona), además del propio río Morona (tributario izquierdo del río Marañón); el Bajo y Medio Chapuli, el Bajo Chuinda, el Bajo y Medio Huitoyacu, el lago Rimachi, el Bajo Manchari, el Bajo Huasaga y el lago Anatico (tributarios derechos del río Pastaza), también el río Pastaza (tributario izquierdo del río Marañón) hasta la localidad de Andoas Viejo.

El levantamiento de información se realizó in situ, mediante el registro escrito, gráfico y fotográfico de los sitios arqueológicos y materiales culturales arqueológicos observados en superficie y en posesión de algunos pobladores locales. También, dependiendo de las características del terreno y la accesibilidad a los sitios de muestreos, se efectuaron croquis de ubicación, dimensión y características fisiográficas de los sitios arqueológicos. El reconocimiento arqueológico sistemático comprendió el interior y alrededores de las comunidades, el patio y huerto de las viviendas, los caminos y trochas, las chacras, las purmas, el interior del bosque, y los taludes de los ríos y quebradas. El recorrido de la zona se realizó a pie y en bote (Foto $\mathrm{N}^{\mathrm{o}} 1$ ).

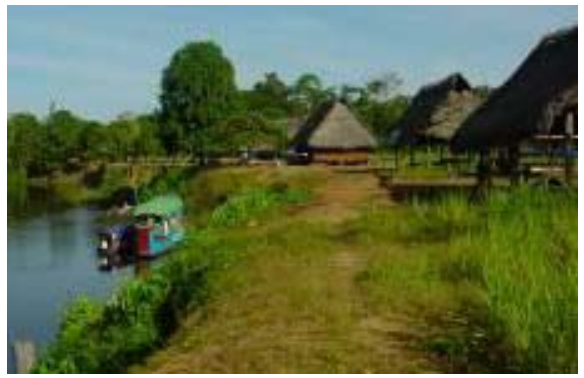

Foto 1.

Vista de la Comunidad candoshi Nueva Yarina

(Sitio arqueológico Nueva

Yarina), río Chapuli.

(Mayo 2006. Foto: Julio

Abanto Llaque)

Financiado por el Fondo Nacional para Áreas Naturales Protegidas por el Estado (PROFONAMPE), bajo el Proyecto Manejo de los Recursos Naturales en las cuencas de los ríos Pastaza Morona, el marco del Plan Binacional de Desarrollo de la Región Fronteriza PerúEcuador, que se rige por el Convenio Intergubernamental Peruano Alemán. La ejecución del Proyecto de ZEE Pastaza Morona lo realizó la Facultad de Ciencias Forestales de la Universidad Nacional de la Amazonía Peruana, siendo Decano el Ing. M.Sc. Jorge M. Espíritu Pezantes.

$7 \quad$ Es la primera vez que en una ZEE se incluye el componente arqueológico, en la Amazonía Peruana, a propuesta del Ing. Dr. Salvador Flores Paytán. En él participaron los coautores del presente artículo. El documento, desde su etapa inicial hasta la parte final del informe (Febrero de 2007), pasó por la revisión del Ing. M.Sc. Richer Ríos Zumaeta. El arqueólogo M.Sc. Daniel Morales Chocano (Asesor Externo), hizo una revisión del documento, previo a la presentación del Informe Final. La elaboración del Mapa de sitios arqueológicos del área de estudio estuvo a cargo de la Ing. Corina Caldas Carrillo. Todo el estudio tuvo una duración de 12 meses calendáricos. 


\begin{tabular}{|c|c|c|c|c|c|c|c|c|c|c|}
\hline 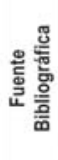 & 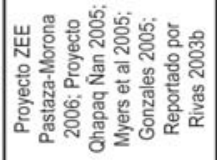 & 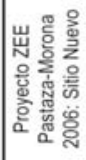 & 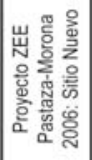 & 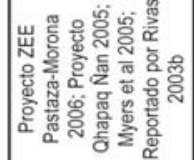 & 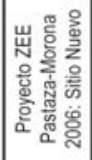 & 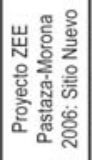 & 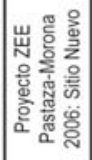 & 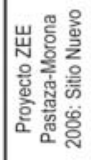 & 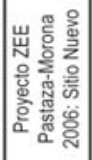 & 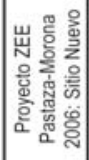 \\
\hline 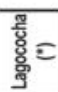 & $\times$ & $\times$ & $\times$ & $\times$ & $\times$ & $\times$ & $\times$ & 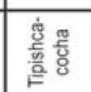 & 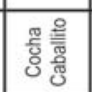 & $\times$ \\
\hline 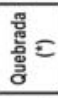 & $\times$ & $\times$ & $\times$ & $\times$ & $\times$ & 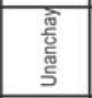 & $\times$ & $\times$ & $\times$ & $\times$ \\
\hline 吾 & $\times$ & $\times$ & $\times$ & $x$ & $\times$ & 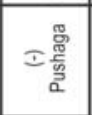 & $\times$ & $\times$ & $x$ & $\times$ \\
\hline 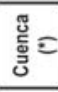 & 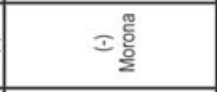 & ᄃ产 & 玉 & I焉 & I芯 & = & 玉总 & 玉至 & 玉 & 玉 \\
\hline 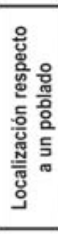 & 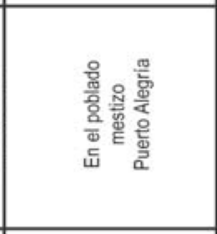 & 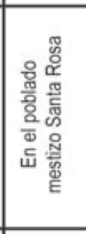 & 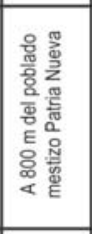 & 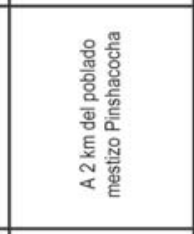 & 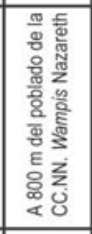 & 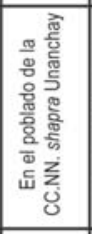 & 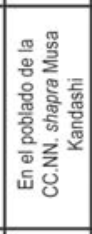 & 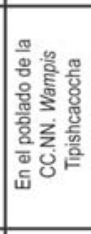 & 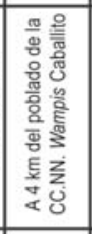 & 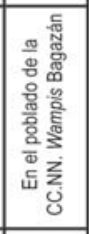 \\
\hline $\begin{array}{l}\text { 음 } \\
\text { 응을 } \\
=\frac{0}{0}\end{array}$ & 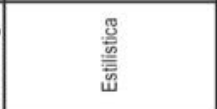 & 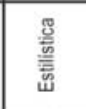 & 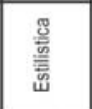 & 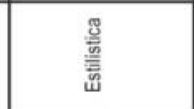 & 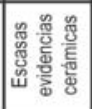 & 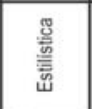 & 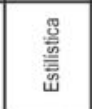 & 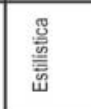 & 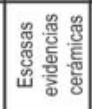 & $\begin{array}{l}\text { 吕 } \\
\text { 譬 } \\
\text { w }\end{array}$ \\
\hline 宅 & 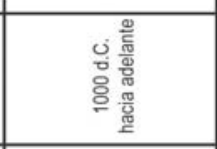 & 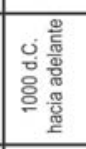 & 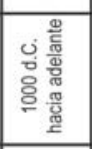 & 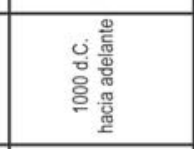 & 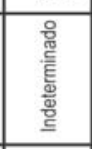 & 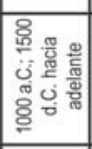 & 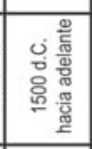 & 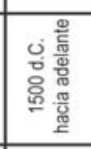 & 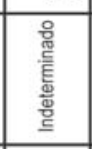 & 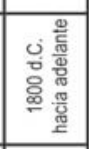 \\
\hline 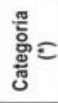 & 离兽 & 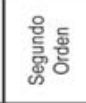 & 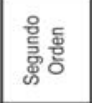 & 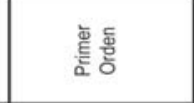 & 递 あ⿸丆口̆ & 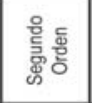 & 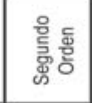 & 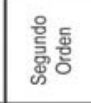 & 屯্ّ & 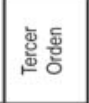 \\
\hline 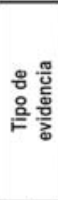 & 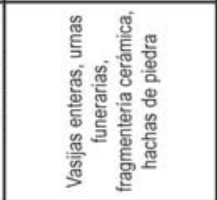 & 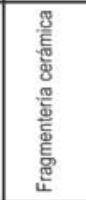 & 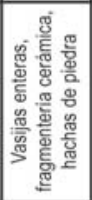 & 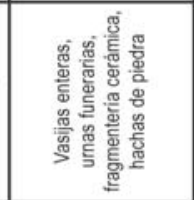 & 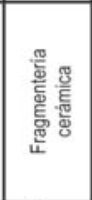 & 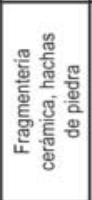 & 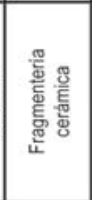 & 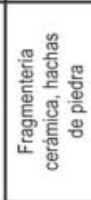 & 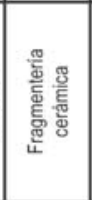 & 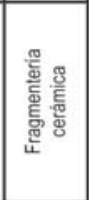 \\
\hline 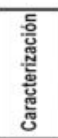 & 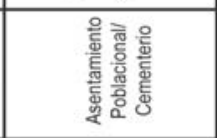 & 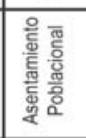 & 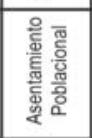 & 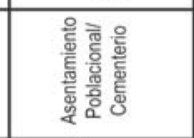 & 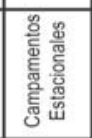 & 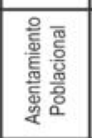 & 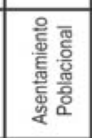 & 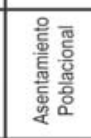 & 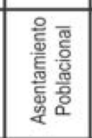 & 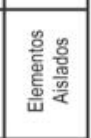 \\
\hline 욤 & 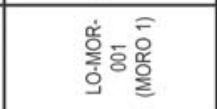 & ํㅜㅇ & 产 & 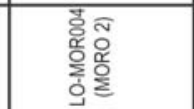 & 产 & $\sum_{0}^{\circ}$ & 产 & 훙 & ํㅜㅇ영 & 홍응 \\
\hline 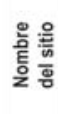 & $\begin{array}{l}\text { 은 } \\
\text { 要 } \\
\frac{10}{4}\end{array}$ & 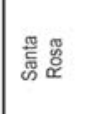 & 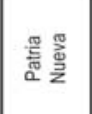 & త骂 & 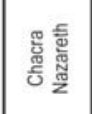 & 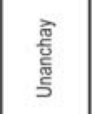 & 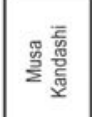 & 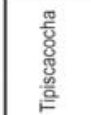 & 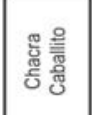 & 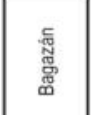 \\
\hline$\cong$ & - & $\sim$ & $m$ & + & in & 0 & r & $\infty$ & o & $\therefore$ \\
\hline
\end{tabular}




\begin{tabular}{|c|c|c|c|c|c|c|c|c|c|c|c|c|}
\hline 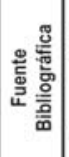 & 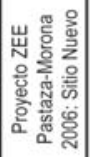 & 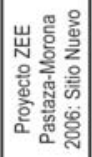 & 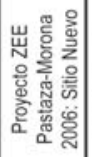 & 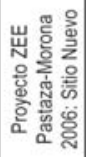 & 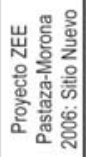 & 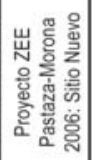 & 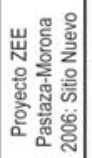 & 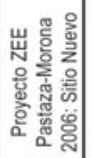 & 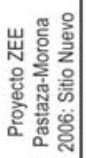 & 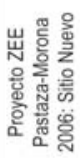 & 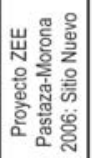 & 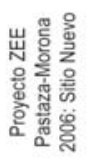 \\
\hline $\begin{array}{l}\frac{5}{8} \\
\frac{8}{8} \\
\frac{6}{9}\end{array}$ & $\times$ & $\times$ & $\times$ & $\times$ & $\times$ & $\times$ & $\times$ & $\times$ & $\times$ & $\times$ & $\times$ & $\times$ \\
\hline 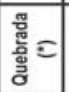 & $\times$ & 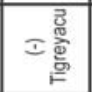 & $\times$ & $\times$ & $\times$ & $\times$ & $\times$ & $\times$ & $\times$ & $\times$ & $\times$ & $\times$ \\
\hline 点 & $\times$ & $\times$ & $\times$ & $x$ & $\times$ & $\times$ & $\times$ & 王橧 & $\times$ & $\times$ & こ言 & こ言 \\
\hline 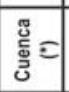 & 玉 & 玉 & 厂兽 & 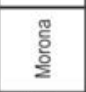 & 玉 & 厂气 & 厂总 & = & 玉总 & 工客 & 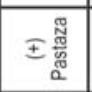 & 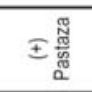 \\
\hline 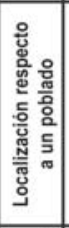 & 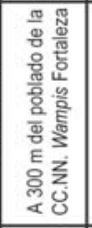 & 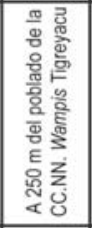 & 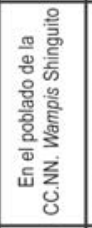 & 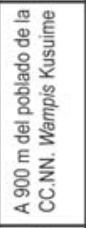 & 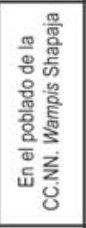 & 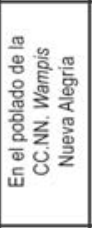 & 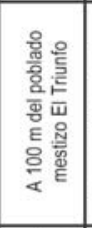 & 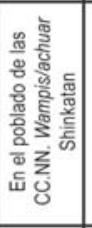 & 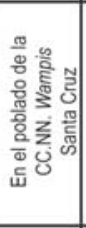 & 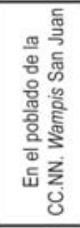 & 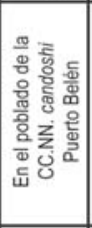 & 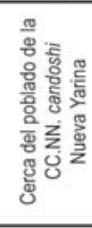 \\
\hline 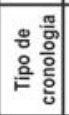 & 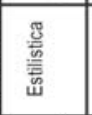 & 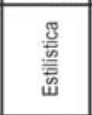 & 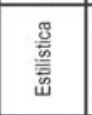 & 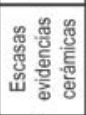 & 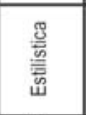 & 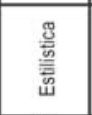 & 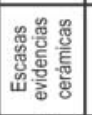 & 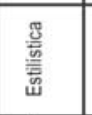 & 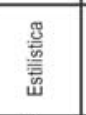 & 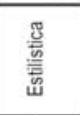 & 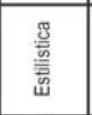 & 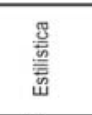 \\
\hline : & 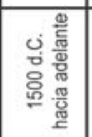 & 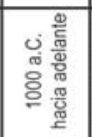 & 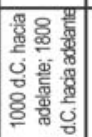 & 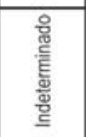 & 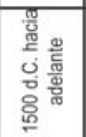 & 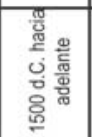 & 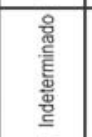 & 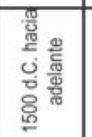 & 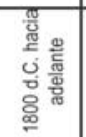 & 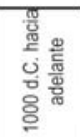 & 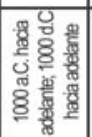 & 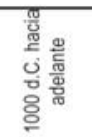 \\
\hline 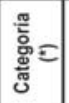 & 递 要 & $\begin{array}{l}\text { 윯. } \\
\text { 행ㅎㅀ }\end{array}$ & 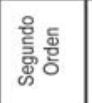 & 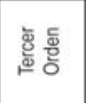 & 兽总 & 惡 & 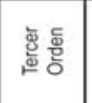 & 产 ㅎ̆ㅇ & 竜总 & 衰 & 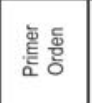 & 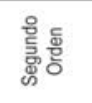 \\
\hline 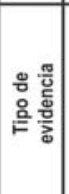 & 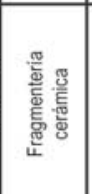 & 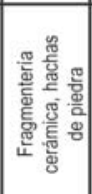 & 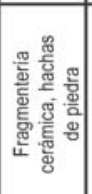 & 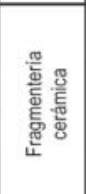 & 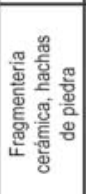 & 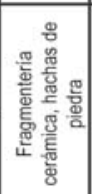 & 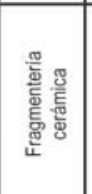 & 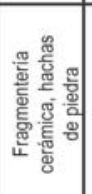 & 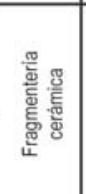 & 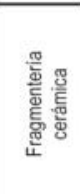 & 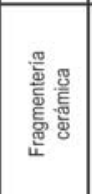 & 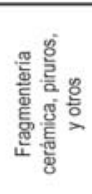 \\
\hline 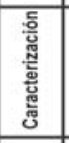 & 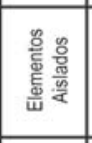 & 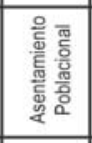 & 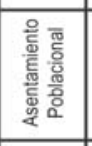 & 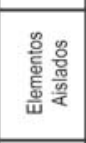 & 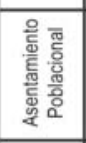 & 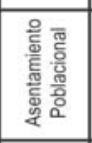 & 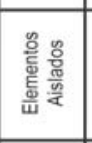 & 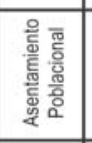 & 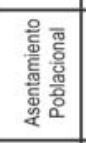 & 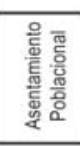 & 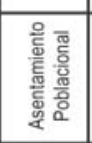 & 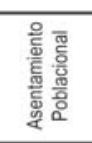 \\
\hline : & 产 & ํㅜㅇ엉 & 产옹 & 产 & $\sum_{0}^{0}$ & 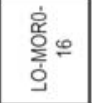 & 递 & $\sum_{0}^{\circ}$ & 웅훙 & 웅정 & $\begin{array}{l}\text { d. } \\
\text { 空 } \\
\text { த் }\end{array}$ & 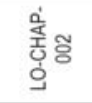 \\
\hline 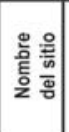 & 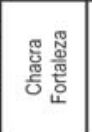 & 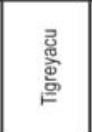 & $\begin{array}{l}\text { 을 } \\
\text { 产 } \\
\text { क }\end{array}$ & 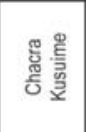 & $\begin{array}{l}\frac{\pi}{\pi} \\
\frac{0}{\pi} \\
\text { कँ }\end{array}$ & 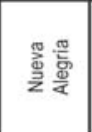 & 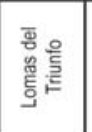 & 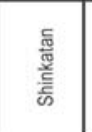 & 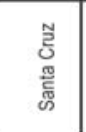 & 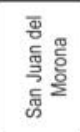 & 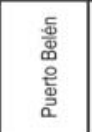 & 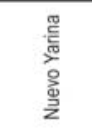 \\
\hline 으 & $=$ & $\simeq$ & m & \pm & $\dddot{2}$ & 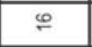 & $=$ & $\stackrel{\infty}{-}$ & 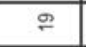 & ని & $\bar{\sim}$ & ส \\
\hline
\end{tabular}




\begin{tabular}{|c|c|c|c|c|c|c|c|c|c|c|c|c|}
\hline 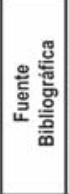 & 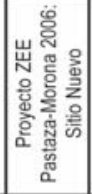 & 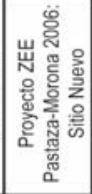 & 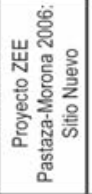 & 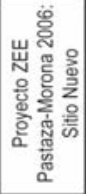 & 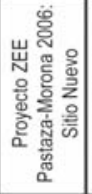 & 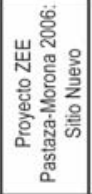 & 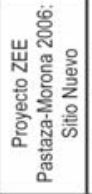 & 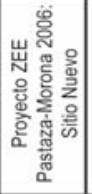 & 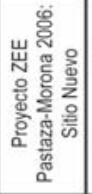 & 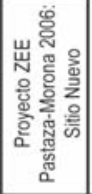 & 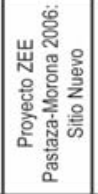 & 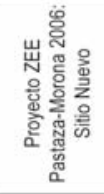 \\
\hline 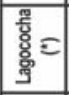 & $\times$ & $\times$ & $\times$ & $\times$ & $x$ & $\times$ & $\times$ & $\times$ & $x$ & 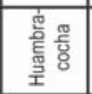 & 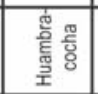 & $\times$ \\
\hline 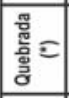 & $\times$ & $\times$ & $\times$ & $\times$ & $\times$ & $\times$ & $\times$ & $\times$ & $\times$ & $\times$ & $x$ & $\times$ \\
\hline 荺 & 今言 & 王言 & 今言 & こ言 & 厂言 & 主言 & 工言 & こ言 & 王言 & 二言 & 玉言亭 & 戸总 \\
\hline 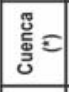 & 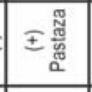 & 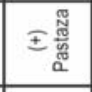 & 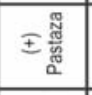 & 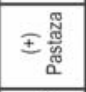 & 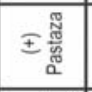 & 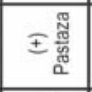 & 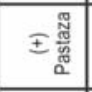 & 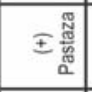 & 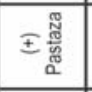 & 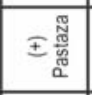 & 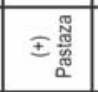 & 王䍃 \\
\hline 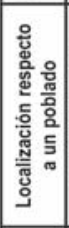 & 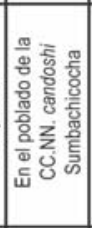 & 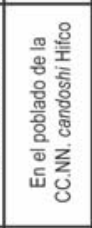 & 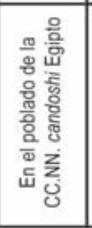 & 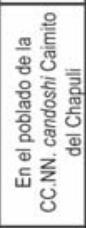 & 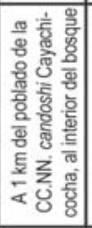 & 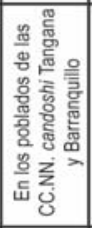 & 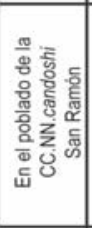 & 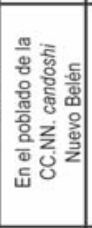 & 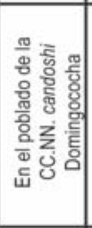 & 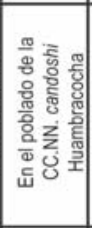 & 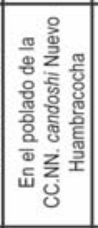 & 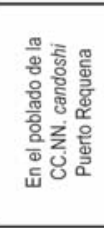 \\
\hline 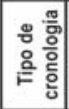 & 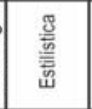 & 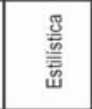 & 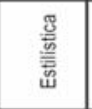 & 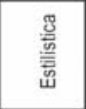 & 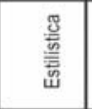 & 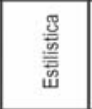 & 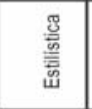 & 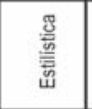 & 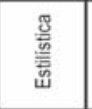 & 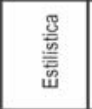 & 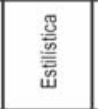 & 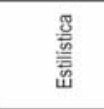 \\
\hline 荌 & 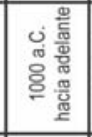 & 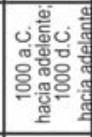 & 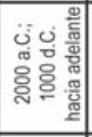 & 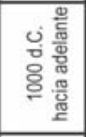 & 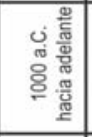 & 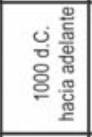 & 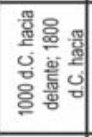 & 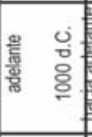 & 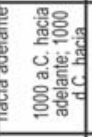 & 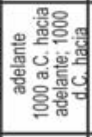 & 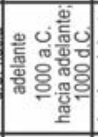 & 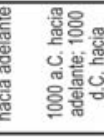 \\
\hline 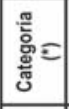 & 倦兽 & 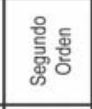 & 离 & 倦要 & 离 & 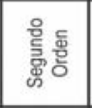 & 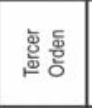 & 离 & 离兽 & 离 & 高 & 离 \\
\hline 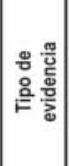 & 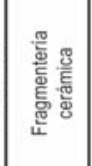 & 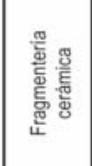 & 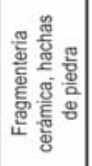 & 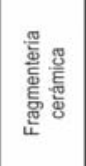 & 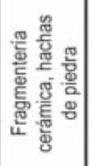 & 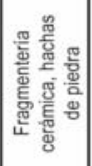 & 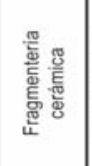 & 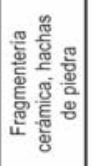 & 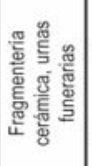 & 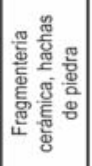 & 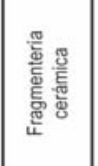 & 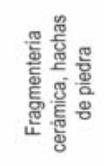 \\
\hline 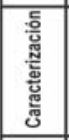 & 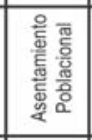 & 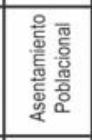 & 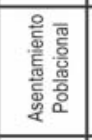 & 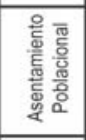 & 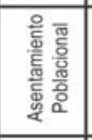 & 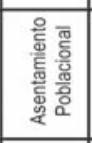 & 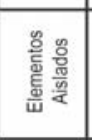 & 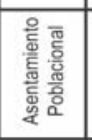 & 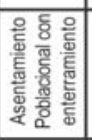 & 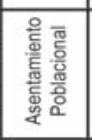 & 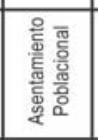 & 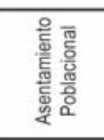 \\
\hline 兽 & 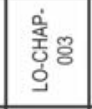 & 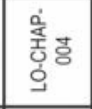 & 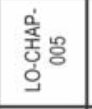 & 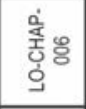 & 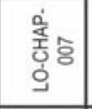 & 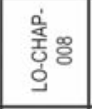 & 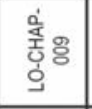 & 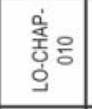 & 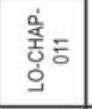 & 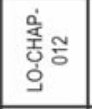 & 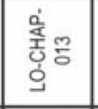 & 突 \\
\hline 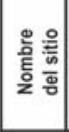 & 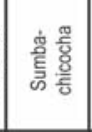 & $\frac{8}{\frac{8}{x}}$ & 윰 & 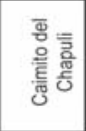 & 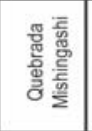 & 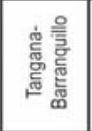 & 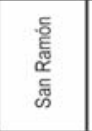 & 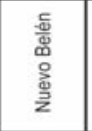 & 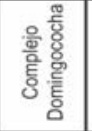 & 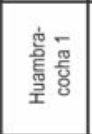 & 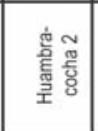 & 을 을 \\
\hline 으 & $\approx$ & ন & $\stackrel{2}{\sim}$ & $\mathbb{2}$ & $\hat{N}$ & $\stackrel{\infty}{\infty}$ & ని & 요 & $\bar{m}$ & ల్ల & m & स्ల \\
\hline
\end{tabular}




\begin{tabular}{|c|c|c|c|c|c|c|c|c|c|c|c|c|}
\hline 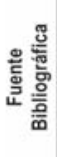 & 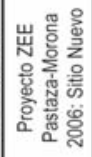 & 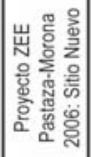 & 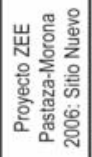 & 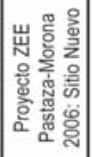 & 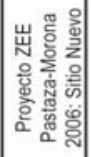 & 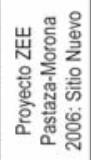 & 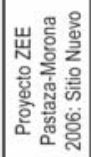 & 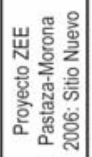 & 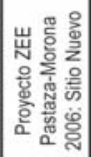 & 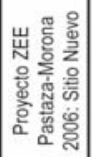 & 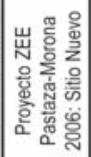 & 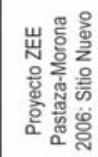 \\
\hline 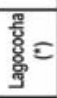 & $\times$ & $\times$ & $x$ & $\times$ & $\times$ & $\times$ & $\times$ & 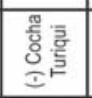 & 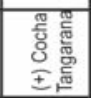 & $x$ & $\times$ & $\times$ \\
\hline 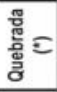 & $\times$ & $\times$ & $\times$ & $\times$ & $\times$ & $\times$ & $\times$ & $\times$ & $\times$ & $\times$ & $\times$ & $\times$ \\
\hline 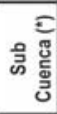 & 王彦 & 王兽 & 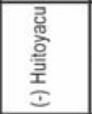 & 增 & 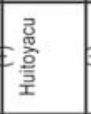 & 土焉 & 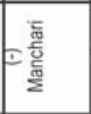 & 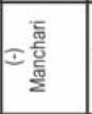 & 王吉 & 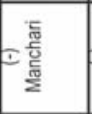 & 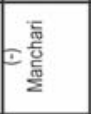 & 玉惡 \\
\hline 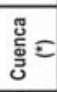 & 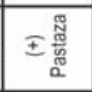 & 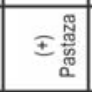 & 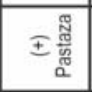 & 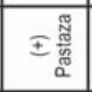 & 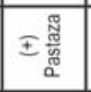 & 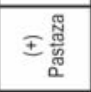 & 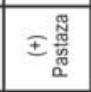 & 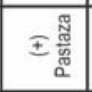 & 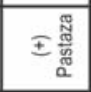 & 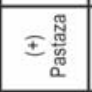 & 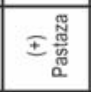 & 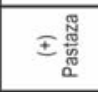 \\
\hline 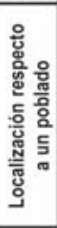 & 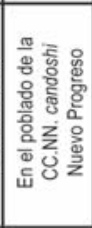 & 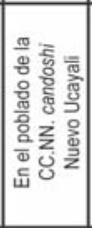 & 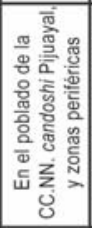 & 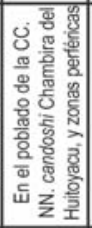 & 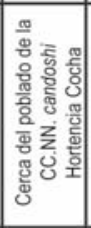 & 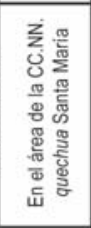 & 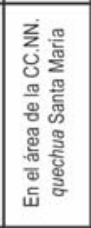 & 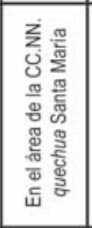 & 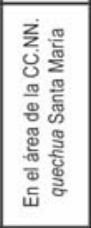 & 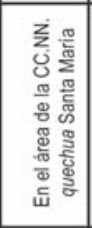 & 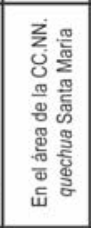 & 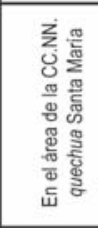 \\
\hline 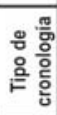 & 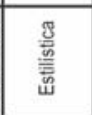 & 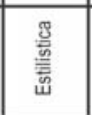 & 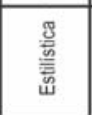 & 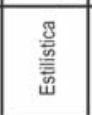 & 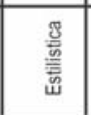 & 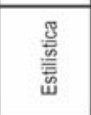 & 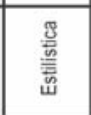 & 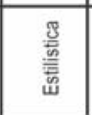 & 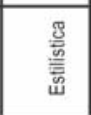 & 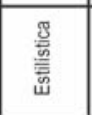 & 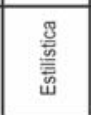 & 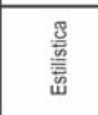 \\
\hline 题 & 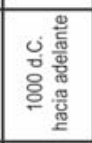 & 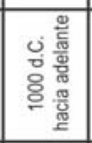 & 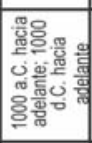 & 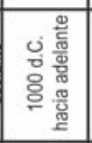 & 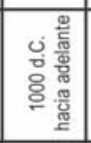 & 总 & 宫. & 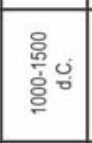 & 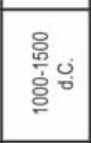 & 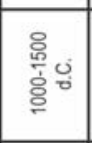 & 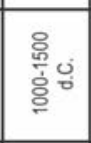 & ن. \\
\hline 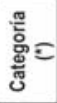 & 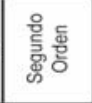 & 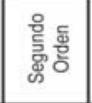 & 哀离 & 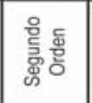 & 屯 & 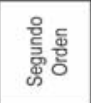 & 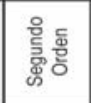 & 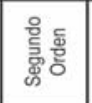 & 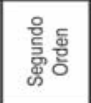 & 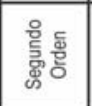 & 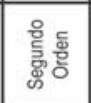 & $\begin{array}{l}\text { 을. } \\
\text { ్ㅐㅎㅀ }\end{array}$ \\
\hline 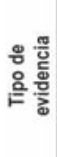 & 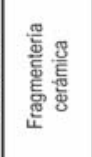 & 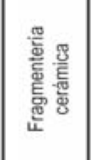 & 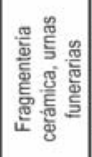 & 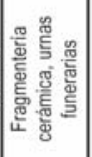 & 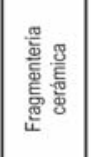 & 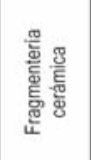 & 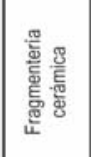 & 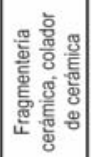 & 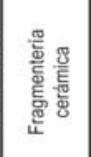 & 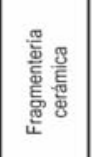 & 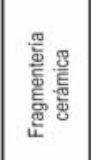 & 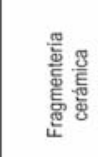 \\
\hline 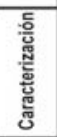 & 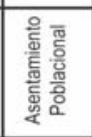 & 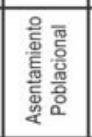 & 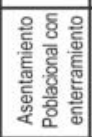 & 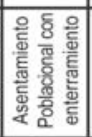 & 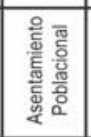 & 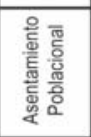 & 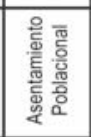 & 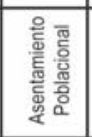 & 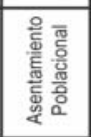 & 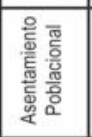 & 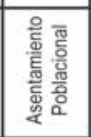 & 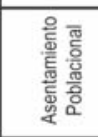 \\
\hline : & 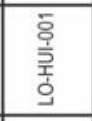 & 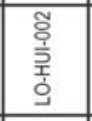 & $\begin{array}{l}\text { \% } \\
\text { 옹 } \\
\text { 퐁 } \\
\end{array}$ & \begin{tabular}{|l|} 
홍 \\
홓 \\
퐁 \\
\end{tabular} & \begin{tabular}{l}
\multicolumn{6}{c}{} \\
홍 \\
종 \\
\end{tabular} & 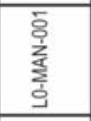 & 충잉 & 产方 & 홍형 & 产递 & 戠易 & 袠 \\
\hline 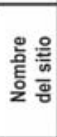 & 总递 & $\begin{array}{l}\text { 量 } \\
\text { 爵 }\end{array}$ & $\begin{array}{l}\text { 丞 } \\
\text { 爱 } \\
\text { a }\end{array}$ & 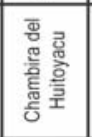 & 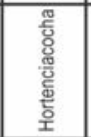 & 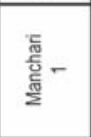 & 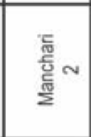 & 总 & 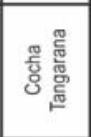 & 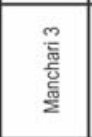 & 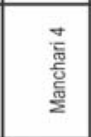 & 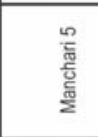 \\
\hline ㅇ & $\mathscr{m}$ & $\mathscr{e}$ & 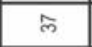 & m & g & 앙 & $\bar{\sigma}$ & $\approx$ & 9 & 7 & ? & \& \\
\hline
\end{tabular}




\begin{tabular}{|c|c|c|c|c|c|c|c|c|c|c|}
\hline 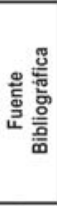 & 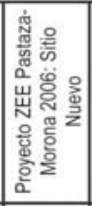 & 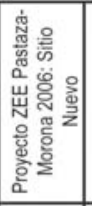 & 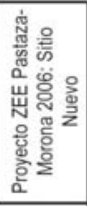 & 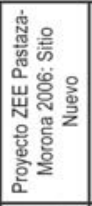 & 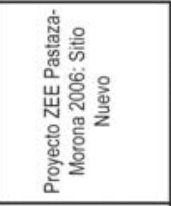 & 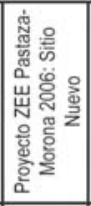 & 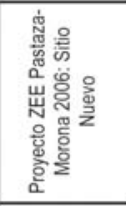 & 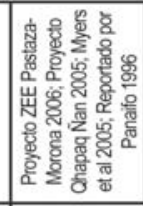 & 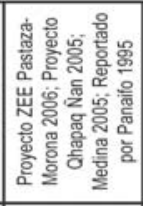 & 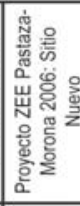 \\
\hline 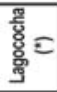 & $\times$ & $\times$ & $\times$ & 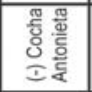 & $\times$ & 욤욤 & 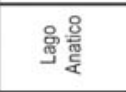 & 욤용 & $\times$ & $\times$ \\
\hline 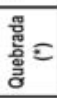 & $\times$ & $\times$ & $\times$ & $\times$ & $\times$ & $\times$ & $\times$ & $\times$ & $\times$ & $\times$ \\
\hline 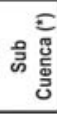 & 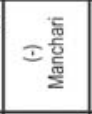 & = & 王营 & $\begin{array}{r}\text { 总 } \\
\text { 惫 } \\
\text { 胥 }\end{array}$ & 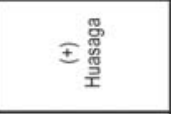 & 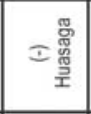 & 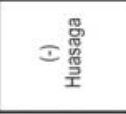 & 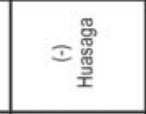 & $\times$ & $\times$ \\
\hline 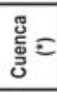 & 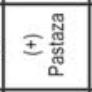 & 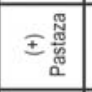 & 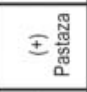 & 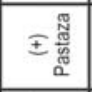 & 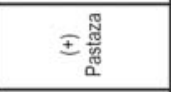 & 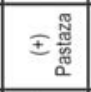 & 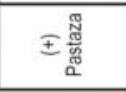 & 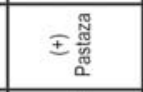 & 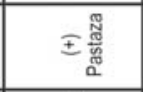 & 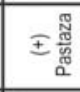 \\
\hline 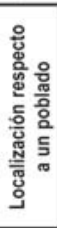 & 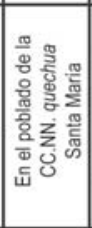 & 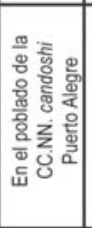 & 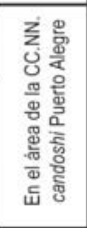 & 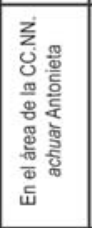 & 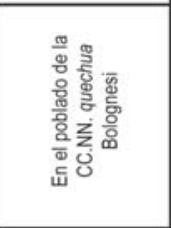 & 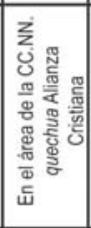 & 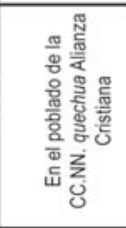 & 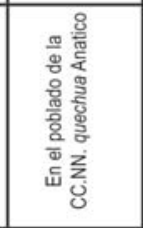 & 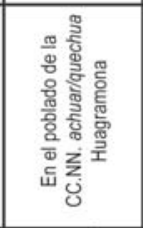 & 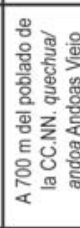 \\
\hline 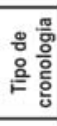 & 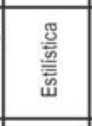 & 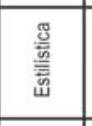 & 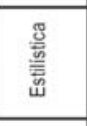 & 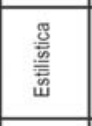 & 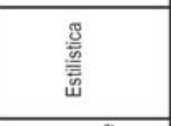 & 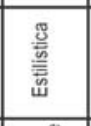 & 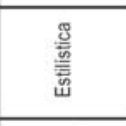 & 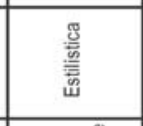 & 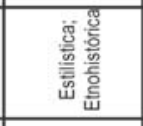 & 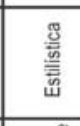 \\
\hline & 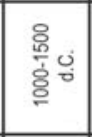 & 荌 & 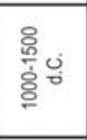 & $\begin{array}{l}0 \\
\mathbb{\pi} \\
8 \\
0\end{array}$ & 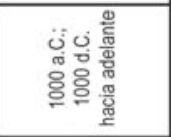 & 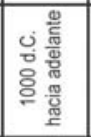 & 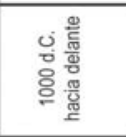 & 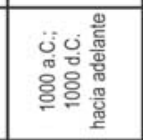 & 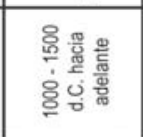 & 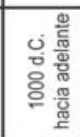 \\
\hline 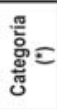 & 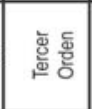 & 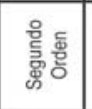 & 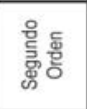 & 巡 & 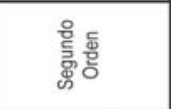 & 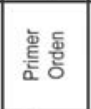 & 홍 & 高 & 离兽 & $\begin{array}{l}\text { 율. } \\
\text { 总 }\end{array}$ \\
\hline 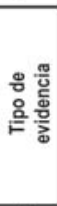 & 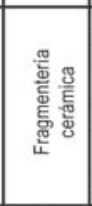 & 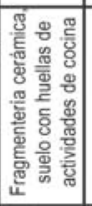 & 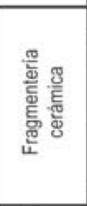 & 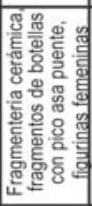 & 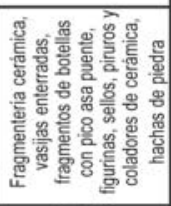 & 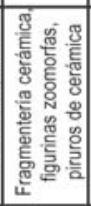 & 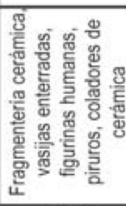 & 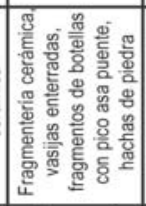 & 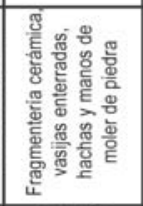 & 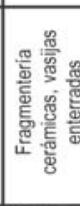 \\
\hline 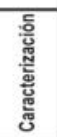 & 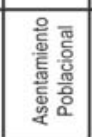 & 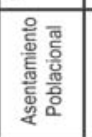 & 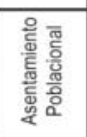 & 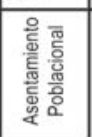 & 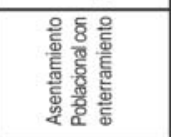 & 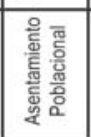 & 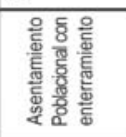 & 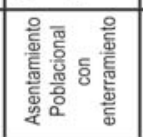 & 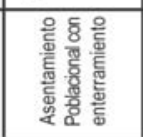 & 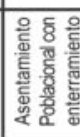 \\
\hline : & 훙잉 & 案。 & 홍응 & $\begin{array}{l}\bar{\delta} \\
\text { 寀 } \\
\text { s. }\end{array}$ & 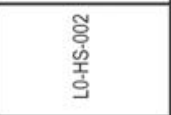 & 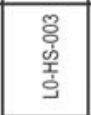 & 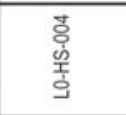 & 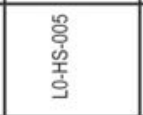 & 容 & 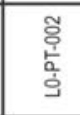 \\
\hline 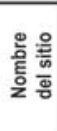 & 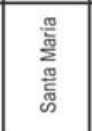 & 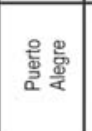 & 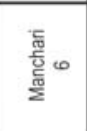 & 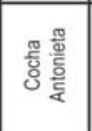 & 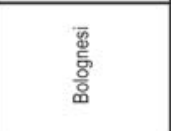 & $\frac{\overline{8}}{\frac{8}{80}}$ & 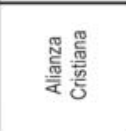 & $\frac{8}{\frac{8}{\pi}}$ & 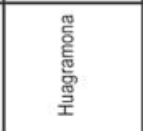 & 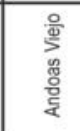 \\
\hline ? & f & $\stackrel{\infty}{7}$ & g & 8 & is & $\widetilde{\sigma}$ & ஜ & \& & $\stackrel{\circ}{\circ}$ & 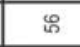 \\
\hline
\end{tabular}


Se registraron un total de 56 sitios arqueológicos (Cuadro $\mathrm{N}^{\circ} 1$ ), de los cuales 52 son nuevos e inéditos en la arqueología amazónica, los otros 04 ya habían sido reportados anteriormente. Las antigüedades estimadas de estas poblaciones, sobre la base de comparación estilística de los materiales culturales, fundamentalmente cerámica, oscilan entre 2000 a.C. hasta 1800 d.C. aproximadamente.

\section{Características del paisaje en el área de estudio}

El Estudio de la MESOZEE Pastaza - Morona abarca un área de 1735899 ha, que representa el 40,76\% de la superficie de la provincia Datem del Marañón.

Toda el área es una zona con características ecológicas de Bosque Húmedo Tropical y con relieves de poca altura que conforman parte del llano amazónico o selva baja (Pulgar Vidal, 1985). Climáticamente se caracteriza por recibir precipitaciones pluviales anuales entre los 2900 y $4000 \mathrm{~mm}$. Incluye suelos de profundidad variable (ONERN, 1984). Entre las especies de flora y fauna se tiene una vegetación natural con predominancia de árboles leñosos para los suelos no inundables y diversas palmeras entre las que destacan el aguaje para las terrazas bajas; animales como el venado, la sachavaca, el sajino, la huangana; aves como el guacamayo, la pava, la garza, los loros; peces como la lisa, el sábalo, la doncella, el paco, la corvina, entre otros.

Una característica con relevancia cultural es el marco hidrográfico de estas cuencas, con numerosos cursos de aguas interconectados. Así, las cuencas del Morona, Pastaza, Santiago y Tigre se vinculan entre sí a través de los ríos menores en cuyas cabeceras o divortium acuarium el paso de un lado a otro a través de los varaderos se da a pocos kilómetros de distancia. Todos estos ríos, a su vez, se comunican directa o indirectamente con el Marañón, y éste con el Huallaga, Ucayali y Amazonas. Además, mirando hacia el norte, los ríos originarios de la Cordillera Oriental del Ecuador se interconectan con las áreas andinas y éstas con las de la costa.

La hidrografía descrita es un factor muy importante en el desarrollo cultural de la zona, especialmente por el establecimiento de redes o circuitos de intercambio de bienes, que aprovechando estas rutas de comunicación fluvial, conectaron no sólo los grupos humanos de la Amazonía entre sí, sino también entre los grupos de las sociedades de los Andes y la costa con la selva, en todas las direcciones.

El río Morona es un afluente del Bajo Marañón que alcanza en territorio peruano una longitud aproximada de $450 \mathrm{~km}$., se caracteriza por tener un lecho de arena con algunas zonas pedregosas, un régimen regular condicionado en gran parte por lluvias locales y un curso relativamente angosto que varía entre 150 y 80 metros desde la boca hasta su origen, y en los lugares más estrechos presenta un ancho de sólo 65 metros. Tiene un recorrido de pocos tramos rectos y muchas vueltas 
(meandros, los que forman cochas denominas tipishcas), con playas y poco caudal de agua en la época de vaciante.

Los ríos Chapuli, Chuinda y Huitoyacu son tributarios del Bajo Pastaza, siendo el Chapuli y Chuinda a su vez depositarios del lago Rimachi. El acceso a los diferentes puntos se logra únicamente por vía fluvial y lacustre. Estas subcuencas, sobre todo las de la sección baja, están conformadas por suelos inundables, rodeadas de cochas y lagos, siendo las más importantes Rimachi, Huambracocha, Chirapa, Huangana, entre otras.

El Pastaza es un río importante desde el punto de vista de fertilidad de sus suelos, y así como el Morona y el Santiago, nace en la Cordillera de los Andes ecuatorianos, por tanto arrastra y deposita sedimentos fértiles a su suelo, que incluso favorecen también a los suelos del río Marañón, a quien entrega sus aguas en su margen izquierda.

Faura Gaig divide al Pastaza en dos partes: la parte Alta, desde su origen hasta donde desemboca el río Huasaga y la parte Baja, que comprende desde esta desembocadura hasta el río Marañón (Faura Gaig, 1962). Su caudal es difícil de estimar y complejo para la navegación de embarcaciones a motor, condición que favorece la formación de numerosas islas, más de 100 en total en lo que corresponde al territorio peruano, en su recorrido de $420 \mathrm{~km}$.

Los ríos Huitoyacu, Huasaga y Bobonaza, también cordilleranos de Ecuador, son los principales tributarios del Pastaza, desde la margen derecha. Estos ríos de aguas blancas y negras son alimentados por otros ríos, y junto con el Manchari (de $90 \mathrm{~km}$ de longitud), también de aguas negras, desembocan por la margen derecha del Pastaza.

\section{Antecedentes de investigaciones en el área}

Anterior a nuestros estudios, los proyectos de ZEE o de Evaluación Ecológica, no contemplaron los estudios arqueológicos como parte de los aspectos socio económicos o históricos (INADE, 2000; INADE-ECORAE, 2001; INADE, 2002; WWF, 2002). Las empresas petroleras que operan en el país sí han realizado estudios arqueológicos, a nivel de los Estudios de Impacto Ambiental y Social, de los cuales se tiene para el Pastaza y Morona el reporte de una veintena de sitios arqueológicos.

Un estudio entre las cuencas del Alto Morona y Alto Pastaza revela la existencia de una docena de sitios arqueológicos, permitiendo sostener el alto potencial arqueológico para futuras investigaciones en la zona (ERM, 2002). Ada Medina Mendoza también investigó en el Alto Morona, en los ríos Morona, Situche y Anás, por donde están las comunidades Achuar Panintsa y Unkum. Dio cuenta al Instituto Nacional de Cultura del registro de evidencias cerámicas semejantes a las 
encontradas por Morales, Fung y Ravines, y por Porras en el Huasaga ecuatoriano (Medina, 2003, 2004).

Santiago Rivas Panduro hace el primer reporte sobre los sitios arqueológicos Puerto Alegría y La Luna, en el río Morona, los mismos que posteriormente serían declarados Patrimonio Cultural de La Nación por el INC (Rivas, 2003b; Myers et al, 2005). Posteriormente Ada Medina y Consuelo Gonzáles realizaron una evaluación arqueológica de emergencia en el sitio arqueológico Puerto Alegría. Allí recuperaron información y material arqueológico diverso, como vasijas, urnas funerarias, hachas de piedra, entre otros objetos más, destacando los contextos funerarios (Gonzales, 2005).

Myers y Rivas nos muestran material procedente del Huitoyacu, recuperado por pobladores y maestros, que presentan semejanza con la alfarería descrita por Morales, provenientes de sus excavaciones en el río Chambira (Myers et al, 2005: 92). Para el río Huitoyacu Panaifo también reporta un asentamiento en la desembocadura con el Pastaza, probablemente se trate del caserío San Fernando, mientras que para el lago Rimachi da cuenta de la existencia de cuatro sitios arqueológicos ubicados en las islas de dicho lago, aunque su ubicación no es muy precisa (Rivas, 2005b).

El primer trabajo arqueológico en el Alto Huasaga (en la frontera de Ecuador con Perú) fue realizado por el padre Porras, obteniendo una secuencia de varias ocupaciones, que van del período formativo hasta el período tardío (Porras, 1975). Posteriormente, Warren De Boer y sus colegas reportan una cantidad de fragmentos cerámicos también del río Huasaga (lado peruano), que se relacionan con las descubiertas por Porras (De Boer et al, 1977). Luego vienen los trabajos de Mónica Panaifo, a través de sus Estudios de Impacto Ambiental, donde reporta nuevos sitios arqueológicos en el Pastaza y tributarios (Panaifo, 1994a, 1994b, 1995, 1996), y también del arqueólogo Juan Mogrovejo, cuyos reportes aún no han sido publicados.

A fines del 2004, Ada Medina también explora el Pastaza (para OXI, en el Lote 101), desde Andoas Viejo hasta la boca del Huasaga, y de allí hasta el lago Anatico (Medina, 2005). Igualmente, en enero de 2005 Julio Abanto realiza un trabajo arqueológico en el Pastaza, poco más arriba de Andoas (para Plus Petrol, en el Lote $1 \mathrm{AB})$, reportando cuatro sitios arqueológicos (Abanto, 2005 a, 2005b, 2005c). Finalmente, Myers y Rivas (Myers et al, 2005), dan cuenta de la existencia de nuevos sitios arqueológicos en varios ríos tributarios del Bajo Marañón, algunos de cuyos materiales se relacionan con los del Pastaza, otros tributarios del Marañón y también con las culturas cerámicas de la costa ecuatoriana. También tenemos la descripción de algunos fragmentos cerámicos encontrados en la zona del Pastaza por la brigada de Geólogos de la UNMSM (Sánchez et al, 1999). 
Investigaciones arqueológicas que nos ayudan a comprender la temática del Pastaza - Morona lo encontramos en Daniel Morales, referido a las tradiciones alfareras tempranas de la cuenca del Chambira, representadas básicamente por las figurinas femeninas y las botellas con pico y asa (Morales, 1992, 1998).

Merece remarcar que el área del Pastaza - Morona, por la actividad petrolera, ha estado sujeta a estudios de impacto ambiental además de evaluaciones y rescates arqueológicos, por ello esta modalidad ha facilitado desarrollar un mayor rango de información con respecto a las evidencias prehispánicas en la zona. Mención aparte merece el esfuerzo de arqueólogos regionales, como Santiago Rivas (2005a) y Mónica Panaifo (1994a) quienes de manera constante vienen produciendo y ordenando la información dispersa con la finalidad de lograr un panorama más acertado del desarrollo cultural en la zona (Rivas, 2005b).

Entre los arqueólogos que trabajaron en la costa, sierra y selva ecuatoriana, y cuyos materiales culturales van a estar relacionados con los de la cuenca del Pastaza - Morona, tenemos a Pedro Porras (1975a, 1975b, 1984, 1987), Emilio Estrada (1958, 1962), Betty Meggers y Cliford Evans (1957), entre otros.

A nivel del territorio amazónico peruano, otros aportes importantes relacionados con nuestras investigaciones los encontramos en Donald Lathrap (1970), Thomas Myers (1972, 1976, 1981, 1988), Daniel Morales (2002) Jaime Miasta (1979), Rosa Fung (1981), Rogger Ravines (1981), Ruth Shady (1973) y otros más de generaciones posteriores.

\section{CARACTERIZACIÓN DE LAS OCUPACIONES HUMANAS}

Evaluar el Patrón de Asentamiento así como la demografía y desarrollo cultural en selva baja a partir de fuentes arqueológicas presenta dificultades metodológicas, debido a las condiciones medioambientales que no permiten la conservación de restos orgánicos, y a que la mayor parte del territorio suele estar cubierto por vegetación que impide ubicar otros restos existentes en el subsuelo. Se suma a ello la falta de arquitectura de piedra, por la ausencia de esta materia prima en el llano amazónico, y también por la falta de excavaciones arqueológicas en grandes áreas que nos permitieran entender el modus vivendi de sus pobladores (Rivas, 2006; Rivas et al, 2006). Bajo estas circunstancias, en la llanura amazónica se determina la presencia, tamaño y forma de los asentamientos, en base a la dispersión de cerámica en la superficie del suelo o por la existencia de manchas de tierra negra con asociación a cerámica (Morales, 2000) y por la presencia de algunos artefactos importados de piedra sobre o dentro del suelo.

Las características de los sitios arqueológicos reportados en este estudio nos revelan dos patrones básicos de asentamientos arqueológicos: 
- Asentamientos Arqueológicos Ribereños: Dispuestos a lo largo de las márgenes de los ríos, sobre restingas, terrazas o suelos no inundables. Agrupa a casi la totalidad de los sitios arqueológicos; incluso poblaciones indígenas actuales ocupan estos espacios.

- Asentamientos Arqueológicos Interfluviales: Dispuestos al interior del bosque, sobre terrazas o colinas altas, próximos a quebradas pequeñas.

\section{A. Cuenca del río Morona}

El Patrón Arqueológico de Asentamiento predominante está referido al establecimiento de campamentos en terrazas no inundables, con adecuados índices de drenaje, cercanos a los cauces de ríos (ribereños) y quebradas (intefluviales), sobre suelos que permitieran cierta actividad agrícola, siendo muy probable la presencia de campamentos periféricos a los núcleos base y que, actualmente, estarían cubiertos por la densa vegetación.

Lo que aún no es posible determinar, con los datos obtenidos, es el tipo de vivienda utilizado, aunque la casuística refiere que los asentamientos con viviendas multifamiliares fueron comunes en la cuenca amazónica.

Fundamentados en las observaciones realizadas en las diversas comunidades visitadas, se establece una alta correspondencia entre el actual patrón Etnográfico de Asentamiento y el patrón Arqueológico de Asentamiento, al punto que casi en todas las localidades registradas se encontró superposición o colindancia con áreas que presentaban evidencias arqueológicas (Foto №2).

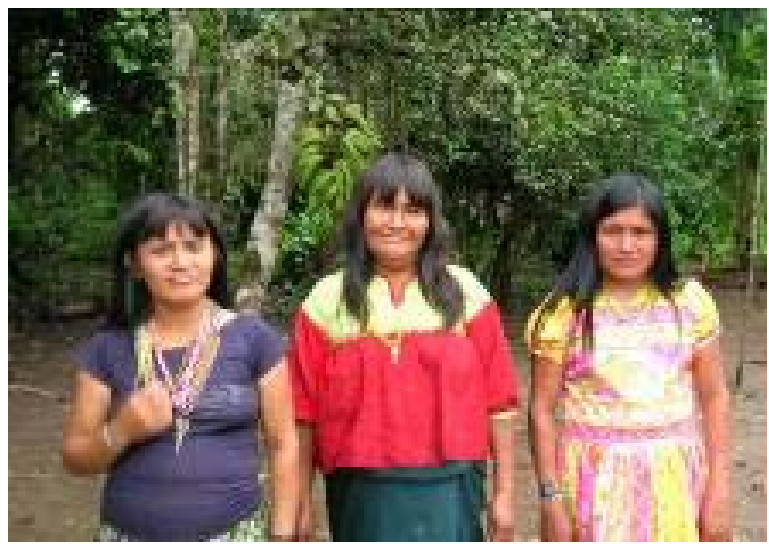

Foto 2.

Mujeres shapra de la CC.NN. Unanchay, río Pushaga.

El poblado coincide con el sitio arqueológico Unanchay.

(Mayo 2006. Foto: Ada Medina Mendoza) 
Investigaciones previas en la cuenca del Morona, ratificadas por esta evaluación, revelaron la presencia de dos antiguos cementerios: el sitio arqueológico La Luna y el sitio arqueológico Puerto Alegría (Gonzales, 2005; Rivas, 2003b; Myers et al, 2005). En estos sitios, con presencia de cementerios densos, el alto volumen de restos encontrados correspondería a asentamientos humanos complejos y grandes, lo que sustentaría la demanda de investigaciones de campo más exhaustivas. Así, en el caso del sitio La Luna, según información proporcionada por los pobladores, estamos hablando de más de 500 urnas funerarias; incluso Rivas reportó testimonios orales de más de 1,000 urnas perdidas por acción de la naturaleza (Rivas, 2003b; Myers et al, 2005), aunque durante nuestro reconocimiento hemos encontrado huellas de excavaciones ilegales que están depredando este importante sitio arqueológico.

Ada Medina y su equipo de arqueólogos registraron en Puerto Alegría más de 25 contextos funerarios con una serie de ofrendas como vasijas y fragmentería de cerámica y hachas de piedra, en un área de apenas $54 \mathrm{~m}^{2}$ (Gonzales 2005). Las coincidencias del patrón de asentamiento, la difícil sostenibilidad de grandes poblaciones en ese entorno y el nomadismo resultante, así como los hallazgos realizados, nos llevan a considerar que tanto el sitio La Luna como el sitio Puerto Alegría podrían presentar sucesivas etapas de asentamiento humano y, por ende, evidencias culturales de diferentes características y filiación cronológica y cultural.

Definitivamente, la concentración de enterramientos en zonas puntuales, como en el caso de Puerto Alegría (zonas Malecón Morona Norte y Malecón Morona Sur) nos estarían indicando que existieron áreas destinadas exclusivamente para ser cementerios de las poblaciones con densos asentamientos, lo que no ocurría ni ocurre con otros grupos relativamente pequeños en los que se ha registrado el uso del espacio doméstico como lugar de entierro.

Por otro lado la iconografía registrada, especialmente el rostro repetido de un personaje antropomorfo, en vasijas provenientes de La Luna (Foto $\mathrm{N}^{\circ} 3$ ) y otros diseños de Puerto Alegría, muestra gran similitud con otras encontradas en el río Pastaza. Nos referimos a la iconografía registrada en Pañayacu (Foto $\mathrm{N}^{\circ} 4$ ) y Huagramona (Foto $\mathrm{N}^{\circ}$ ), en los actuales poblados del mismo nombre, que estimamos tengan un origen etnológico de filiación Záparo (Medina, 2004). Esta afirmación se basa en que este grupo étnico habitó en el área de la antigua Reducción de Pinches, la misma que hoy correspondería a Huagramona. En 1767 los jesuitas dejaron seis (6) Reducciones en el Pastaza, siendo una de ellas San José de Pinches con 200 habitantes (Chantre y Herrera, 1901), lo que explicaría la densidad de bocas de urnas funerarias registradas dentro de esta Comunidad Nativa actual (allí viven achuares y quechuas). La lengua pinche, extinta hoy, perteneció a la familia lingüística Záparo. 


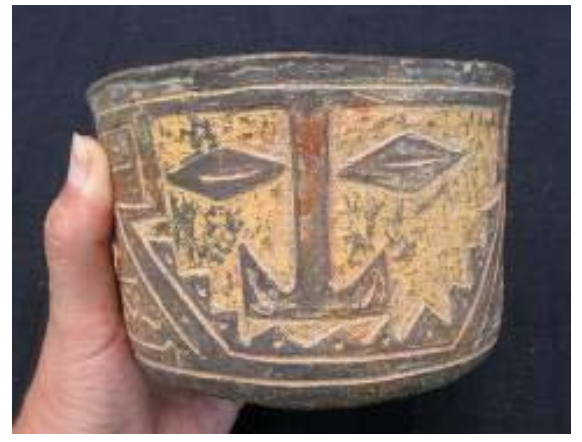

Foto 3.

Vaso del sitio La Luna, río Morona.

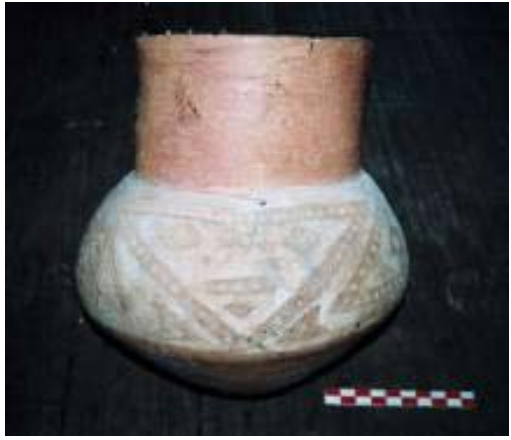

Foto 4.

Tinaja del sitio Pañayacu, río Pastaza.

(Mayo de 2006. Foto: Ada Medina Mendoza). (Mayo 2006. Foto:

Santiago Rivas Pandero)

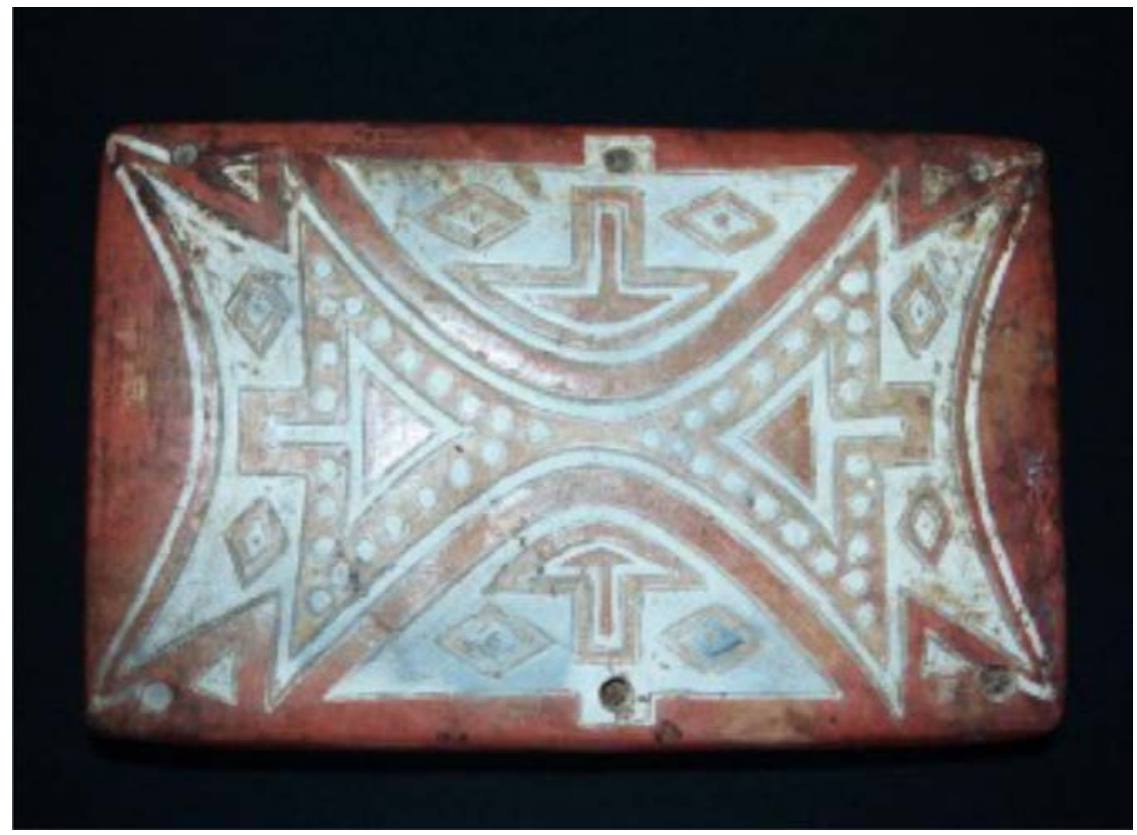

\section{Foto 5.}

Tablilla del sitio Huagramona, río Pastaza.

(Mayo 2006. Foto: Santiago Rivas Pandero) 


\section{B. Subcuencas del Bajo y Medio Chapuli, Bajo Chuinda, Bajo y Medio Huitoyacu}

Los asentamientos que hemos observado en estos tres ríos, se sitúan con mayor regularidad hacia la zona media de la cuenca, de preferencia sobre terrazas no inundables. Este mismo patrón de asentamientos lo señala Morales al efectuar estudios en la cuenca del río Chambira, indicando además que los sitios se disponen a lo largo del curso de los ríos (Morales, 1992: 151). Un detalle importante es la existencia de asentamientos con evidencias alfareras más intensas, las cuales fácilmente afloran a la superficie. Es probable que estos asentamientos sean extensos y ocupen las terrazas circundantes, como lo hemos observado en los sitios de Chambira (río Huitoyacu), Domingococha y Tangana-Barranquillo (río Chapuli).

Sin embargo, un patrón distinto es aquel que se encuentra al interior del bosque, próximo a pequeños caños o quebradas, como es el caso del sitio Mashingashi (río Chapuli), donde además de presentar un estilo alfarero distinto expone el predominio de botellas como forma alfarera destacable (Foto $\mathrm{N}^{\circ} 6$ ).

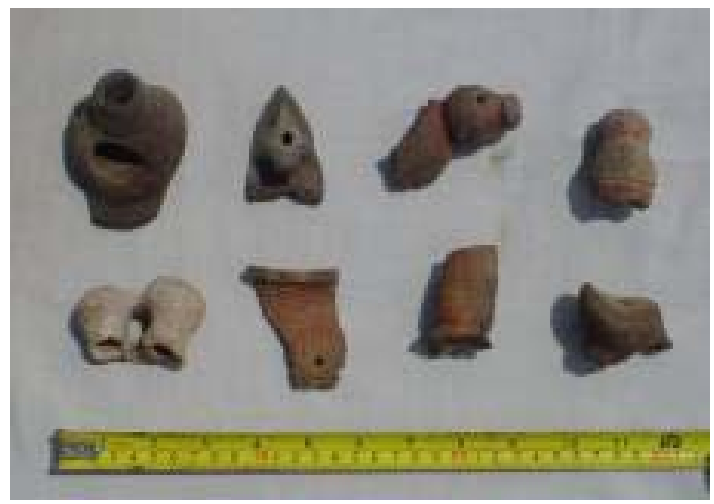

Foto 6.

Evidencias alfareras del sitio arqueológico, quebrada Mashingashi. (Mayo 2006. Foto: Julio Abanto Llaque)

La presencia de urnas, que son vasijas de regular tamaño usadas para depositar cadáveres, nos indica el uso del espacio doméstico como lugar de entierro. No se han podido establecer zonas exclusivas destinadas a cementerios, como ocurre en otros lugares de la selva.

Comparativamente, los materiales alfareros observados en la mayoría de los sitios revelan que se tratan de estilos tardíos que exponen diversas técnicas en su acabado; hasta ahora, no hemos podido establecer si existe una relación directa con las comunidades que actualmente ocupan la zona. Tomas Santillana (2004) hace un 
trabajo documental interesante sobre las etnias que han poblado la cuenca del Pastaza, sin embargo el vacío de no poder ubicar exactamente las etnias, son un fuerte impedimento para establecer desplazamientos de estos pueblos.

En la actualidad las comunidades se asientan en el mismo espacio al de los sitios antiguos. Para el caso de los actuales poblados del río Huitoyacu, sus asentamientos no pasan de los 50 años de fundación; incluso sabemos de poblados que están en proceso de colonizar nuevos espacios (río Chapuli). Un relato recogido de la comunidad de Hortenciacocha (río Huitoyacu) nos ilustra que inicialmente el poblado se encontraba al interior del bosque.

Sin lugar a dudas podemos considerar algunos rasgos de los pueblos actuales para suponer los modos de vida en el pasado, los cuales basan gran parte de su subsistencia en los recursos disponibles en el bosque y en una agricultura de roce y quema. Para el caso de los pueblos de la cuenca baja donde existen abundantes cochas, la actividad principal es la pesca; los asentamientos en zonas altas sustentan su dieta, además de la agricultura de raíces y plátano, con carne proveniente de la caza de animales.

\section{Subcuencas del Bajo Manchari, Bajo Huasaga - Lago Anatico, río Pastaza}

La generalidad de todas las ocupaciones arqueológicas nos muestran que estamos ante poblaciones ribereñas, con asentamientos poblacionales cerca o al borde de la fuente de agua, vale decir en la orilla del río, de la quebrada, lago o cocha. Sólo hay un sitio arqueológico, Cocha Antonieta, que se localiza a unos $200 \mathrm{~m}$ de distancia de la cocha del mismo nombre, lugar donde una habitante local, de la etnia achuar, encontró en su chacra una figurina femenina de arcilla (Foto $\mathrm{N}^{\circ} 7$ ). Es posible que algunos sitios hayan estado un poco apartados de la orilla del río, y que con el tiempo por la acción erosiva del río se los encuentre ahora al borde de la orilla. Como también hay sitios que en parte ya fueron destruidos por la corriente del río, como es el caso del sitio Andoas Viejo.

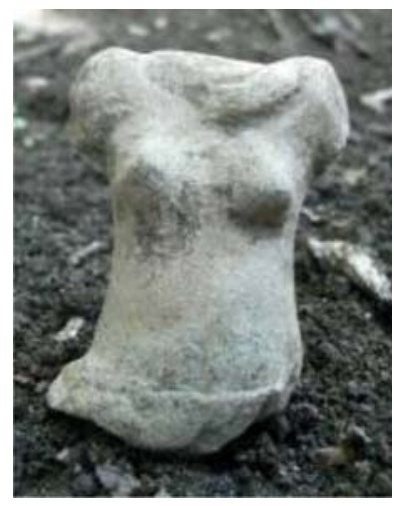

Foto 7.

Figurina femenina de arcilla. Sitio arqueológico Cocha Antonieta, río Huasaga. (Mayo 2006. Foto: Santiago Rivas Panduro) 
Estas características ribereñas de los asentamientos son casi las mismas que se observan ahora en las poblaciones indígenas de esta zona (y también mestizas), quienes suelen escoger sus asentamientos para sus viviendas en suelos de terrazas no inundables, en la orilla del río, quebrada o cocha, y coincidiendo casi por lo general con las antiguas ocupaciones arqueológicas.

La dimensión de los asentamientos tiene que ver con el espacio de terreno no inundable. En el río Manchari, donde hay pequeñas terrazas en ambas márgenes (300 metros de largo a más), las antiguas poblaciones vivían en aldeas pequeñas en extensión, porque no había mayor espacio habitable, pero que en su conjunto toda la población sí era considerable en cantidad. En el río Huasaga se parece seguir el mismo ejemplo.

Pero en el Pastaza, e incluso en el lago Anatico, donde las terrazas de las riberas son más extensas, los asentamientos también tienden a ser de mayores dimensiones. Esto último lo podemos constatar con los sitios Huagramona a orillas del Pastaza (de aproximadamente $6 \mathrm{~km}$ de extensión), y Alianza Cristiana en la ribera del lago Anatico (de más de $1.5 \mathrm{~km}$ de extensión). Estas características nos hacen pensar que las poblaciones arqueológicas, por lo menos para los años 1000 d.C. hacia adelante, eran más densas que las que actualmente viven en estas cuencas.

Todos los sitios arqueológicos reportados en esta investigación son asentamientos poblacionales, pero algunos de ellos además tenían enterramientos, no se sabe si al interior o fuera de las viviendas. La respuesta se podrá dilucidar cuando se realicen excavaciones en el área y se defina la distribución de los espacios. Estos son los casos de los sitios Alianza Cristiana, Bolognesi y Huagramona.

\section{ASPECTOS GENERALES DE LA ARQUEOLOGÍA DEL ÁREA DE ESTUDIO}

\section{A. Cuenca del río Morona}

- $\quad$ El hallazgo y registro de 20 sitios arqueológicos ha permitido establecer un alto potencial arqueológico para la cuenca del río Morona. Una característica con relevancia cultural es el marco hidrográfico de la zona, con numerosos cursos de aguas interconectados que vinculan la cuenca del Morona, con los ríos Santiago, Pastaza y Tigre, y por intermedio de estos con el río Marañón y el propio Amazonas. Esto incluye los ríos de la Cordillera Oriental del Ecuador que se vierten hacia el Sur Este: Zamora, Paute, Upano y Yaupi forman el río Santiago, poco antes de entrar al Perú; los ríos Macuma y Cangaime, sobre la frontera peruano-ecuatoriana, se conectan al río Morona.

- $\quad$ El sistema hidrográfico del área de estudio, fue un factor muy importante en el desarrollo cultural de la misma, especialmente por el establecimiento de redes o circuitos de intercambio de bienes, que aprovechando estas rutas de comunicación fluvial, conectaron no sólo entre sí a los grupos humanos de la 
Amazonía, sino a las sociedades de los Andes con la selva. En el recorrido del área de estudio se han registrado hachas de piedra que revelarían que esta área se insertaba en las redes amazónicas de intercambio de bienes, lo que contribuye a sustentar su potencial arqueológico.

- Se ha reconocido la presencia de tres (3) grupos culturales, para épocas diferentes y con cerámicas de diferentes pastas, formas, decoraciones, que a su vez se relacionan con diversos grupos de la Amazonía, como son:

- Unanchay, caracterizado por la presencia de picos de botella y asociada a cerámica con incisión zonal y punteado (registrado en la CC.NN. de Unanchay).

- La Luna, con una alfarería bastante elaborada procedente del sitio La Luna, donde sobresalen vasijas decoradas con diseños incisos y excisos con pintura post cocción en amarillo y rojo, siendo las formas más comunes cuencos de base plana y escudillas, mientras que las vasijas pequeñas están asociadas a urnas funerarias a manera de ajuar. Estas vasijas pequeñas están decoradas con motivos antropomorfos estilizados y diseños geométricos escalonados, en la que se repite la figura de un personaje de rostro triangular, el mismo que también se ha registrado en vasijas de la cuenca del río Pastaza, e incluso en una vasija procedente de la cuenca del Nucuray (paralelo al Pastaza, y también tributario del Bajo Marañón). La densidad de enterramientos, así como la iconografía compartida, sugieren que La Luna, e incluso Puerto Alegría, serían poblados que presentan elementos históricos, como resultado de su probable condición de antiguas reducciones de nativos.

- Santa Cruz, representada por fragmentos de pasta gruesa con pintura blanca sobre rojo o naranja, de cocción oxidante, con un acabado de superficie alisada que presenta pintura post cocción con diseños geométricos, escalonados y volutas. Las formas más comunes son cuencos, platos y ollas de diverso tamaño. Esta cerámica se registró en un área bien definida en la parte alta del Morona, desde el poblado de Nueva Alegría hasta la boca del río Situche. Cronológicamente esta cerámica sería contemporánea y estaría relacionada con grupos shapras (muratos) en épocas relativamente recientes.

\section{B. Subcuencas del Bajo y Medio Chapuli, Bajo Chuinda, Bajo y Medio Huitoyacu}

- El trabajo de campo nos ha permitido efectuar un reconocimiento cuantitativo y cualitativo de los sitios existentes en estos ríos. En total se han identificado 19 sitios arqueológicos: 13 en la subcuenca del río Chapuli, 1 en la subcuenca del río Chuinda y 5 en la subcuenca del río Huitoyacu. El sitio arqueológico del río Chuinda, Puerto Requena, es el que presenta la mayor cantidad de material visible en la superficie. 
- $\quad$ Podemos afirmar que la cantidad de sitios arqueológicos existentes debe ser superior si consideramos la recopilación de información oral que tenemos al respecto. Estos sitios, como los que se tienen reportados para el lago Rimachi, por las condiciones climáticas imperantes y el nivel en el volumen de agua (creciente, casi desbordando el nivel de la superficie del suelo), nos dificultó nuestra observación haciendo difícil su reconocimiento.

- $\quad$ A grandes rasgos, en las tres cuencas se han podido identificar una serie de estilos alfareros, que podemos contrastar con los reconocidos en otras áreas de la llanura amazónica. Es probable que los materiales observados correspondan a diferentes horizontes culturales siendo mucho más densas las ocupaciones de tradiciones tardías que se emplazan hacia el valle aluvial y las terrazas que lo circundan (Alfar A y Alfar C).

- De los 19 sitios arqueológicos, sólo el sitio Quebrada Mashingashi, corresponde al segundo patrón (Sitios Arqueológicos Interfluviales), el cual expone evidencias alfareras particulares, probablemente de mayor antigüedad (Alfar B) que los Sitios Arqueológicos Ribereños.

Es probable que sobre la base de la densidad de material y difusión de los mismos en el espacio, se plantee la existencia de sitios principales y asentamientos secundarios, un patrón que ya ha sido observado en otras cuencas vecinas. Para ello es necesario efectuar un mayor estudio.

Fundamentados en las evidencias alfareras, podemos preliminarmente definir cuatro (4) fases de materiales:

- Primera Fase «Puerto Egipto»: Corresponde a un grupo de vasijas de color marrón de finos componentes en su pasta, es bastante compacta y con superficie pulida como acabado. Las evidencias se registran debajo estratos con evidencias alfareras tardías. Esta fase parece corresponder a un período anterior a la Fase "Quebrada Mishingashi», por las características de la pasta y profundidad del estrato. Corresponde al Alfar D (Figura $\mathrm{N}^{\circ} 1$ ).

- Segunda Fase "Quebrada Mashingashi»: Se trata de una alfarería bastante elaborada, donde predomina las vasijas muy decoradas, con gruesas líneas incisas y excisas, además de pintura pre y post cocción, destacando los diseños de espirales. Las botellas con pico y asa son una constante entre los materiales observados. Consideramos que debe existir una fase intermedia entre ésta y la primera, aunque por el momento carecemos de evidencias para sustentar tal afirmación. Corresponde al Alfar B. Alfarería semejante ha sido reportada en el sitio Tigreplaya, próximo al pueblo de San Lorenzo, aguas arriba del Marañón; los materiales fueron recogidos por un profesor local, quien ha recuperado 
del barranco material cultural de diversas épocas, entre ellas fragmentería cerámica, fragmentos de botellas con pico asa puente, figurinas zoomorfas, piruros y artefactos líticos (ver Cuadro 2, ID 30).
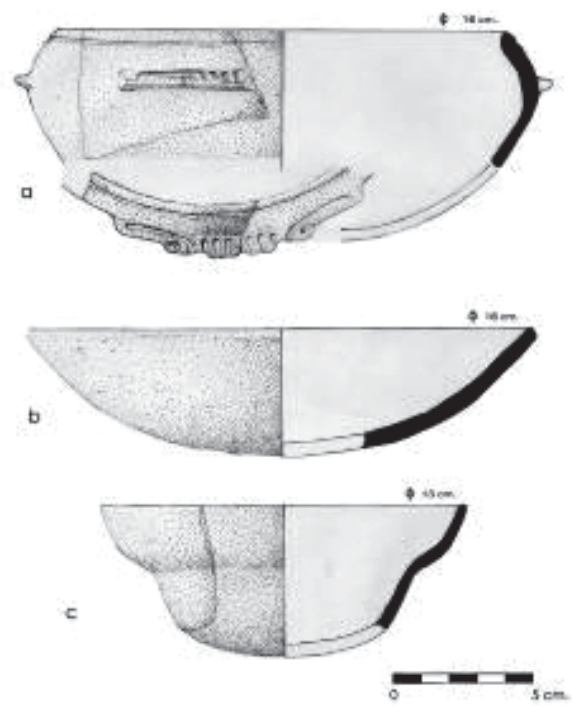

Figura 2.

Frecuencias relativas de tipos no-decorados y decorados en 2 cortes, y su intercaiación.

- Tercera Fase «Estilos Tardíos»: Esta fase puede corresponder a la agrupación de todo un conjunto de estilos que se caracterizan por lograr incorporar diversos rasgos decorativos como el corrugado, digitado, pintura (blanco sobre rojo), estampado, entre otros. Corresponde al Alfar A y Alfar C; se da el uso de piruros, inhaladores de cerámica y coladores para masato.

- Cuarta Fase «Contacto»: Relacionado con los pueblos actuales, se caracteriza por el uso de corteza quemada de apacharama como agregado antiplástico.

\section{Subcuenca del Bajo Manchari}

- En la cuenca del Bajo Manchari hay una amplia y densa ocupación humana para los años 1000 d.C. hacia delante (periodo Intermedio Tardío: 1000- 1500 d.C.), a la que estamos llamando cultura Manchari, y que produjo la cerámica del Alfar 1.

- $\quad$ Este grupo cultural debió dominar toda la cuenca, situación diferente a lo que ocurre hoy en día, donde coexisten tres etnias de familias lingüísticas diferentes: los achuar (familia lingüística Jíbaro) en la cuenca alta; los quechuas 


\begin{tabular}{|c|c|c|c|c|c|c|c|c|}
\hline 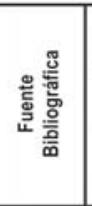 & 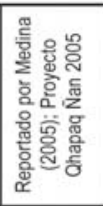 & 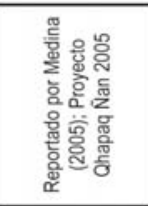 & 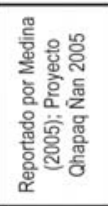 & 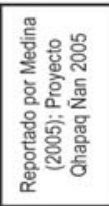 & 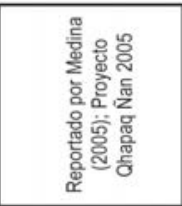 & 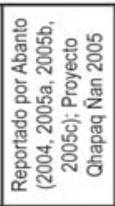 & 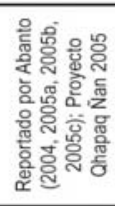 & 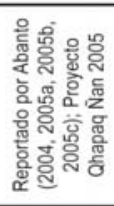 \\
\hline$\frac{\frac{\pi}{m}}{\underline{m}}$ & $\times$ & $\times$ & $\times$ & $\times$ & $\times$ & $\times$ & $\times$ & $\times$ \\
\hline 兽菭 & $x$ & $\times$ & $\times$ & $\times$ & $\times$ & $\times$ & $\times$ & $\times$ \\
\hline 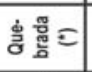 & $\times$ & 要 & $\frac{g}{2}$ & $\times$ & $\times$ & $\times$ & $\times$ & $\times$ \\
\hline 疍 & & & & & & & & \\
\hline 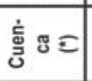 & 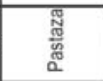 & 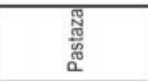 & 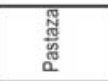 & 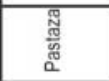 & 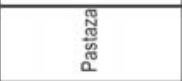 & 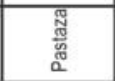 & 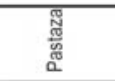 & 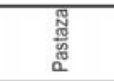 \\
\hline 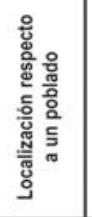 & 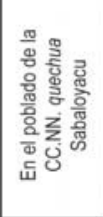 & 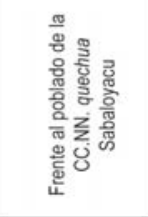 & 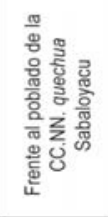 & 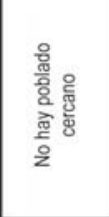 & 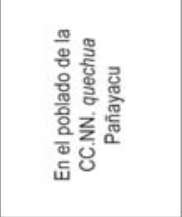 & 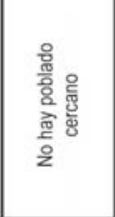 & 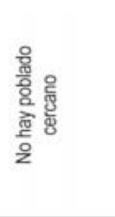 & 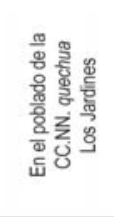 \\
\hline 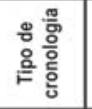 & $\begin{array}{l}\text { 总 } \\
\text { 譬 } \\
\text { w }\end{array}$ & $\begin{array}{l}\text { 总 } \\
\text { 噫 } \\
\text { w }\end{array}$ & 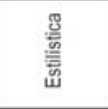 & 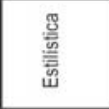 & $\begin{array}{l}\text { 总 } \\
\text { 譬 } \\
\text { 恶 }\end{array}$ & 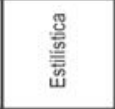 & 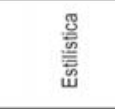 & 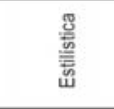 \\
\hline 菖 & 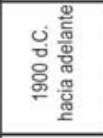 & 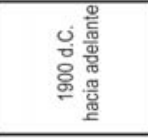 & 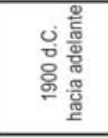 & 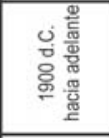 & 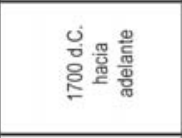 & 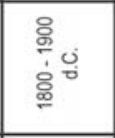 & 灾 & 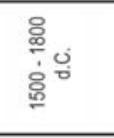 \\
\hline 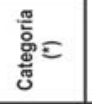 & 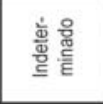 & 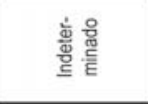 & 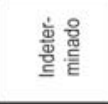 & 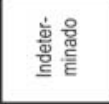 & 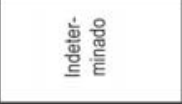 & 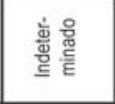 & 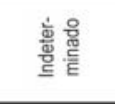 & 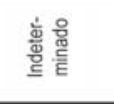 \\
\hline 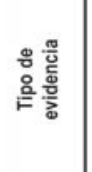 & 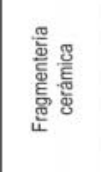 & 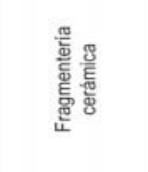 & 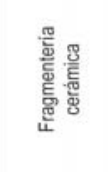 & 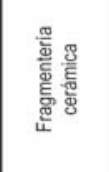 & 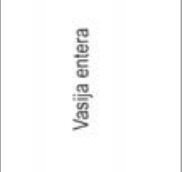 & 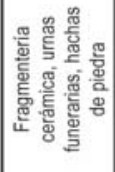 & 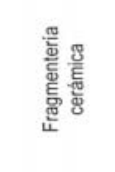 & 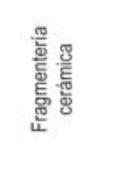 \\
\hline 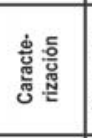 & 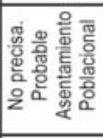 & 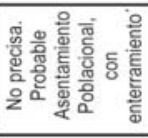 & 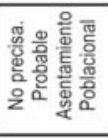 & 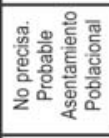 & 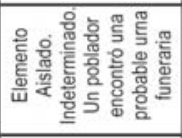 & $\begin{array}{l}\frac{\pi}{3} \\
\frac{\pi}{2} \\
\frac{0}{2}\end{array}$ & 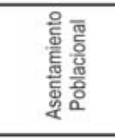 & 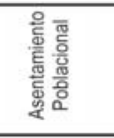 \\
\hline 영 & 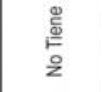 & 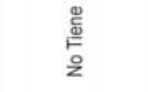 & 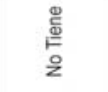 & 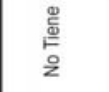 & 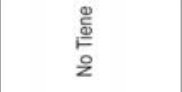 & 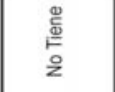 & 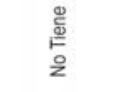 & 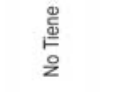 \\
\hline 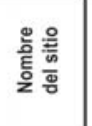 & 总 & 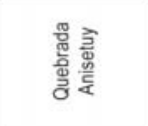 & 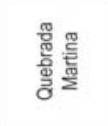 & 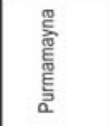 & 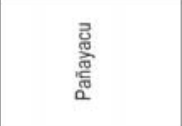 & 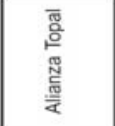 & 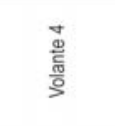 & 器 \\
\hline 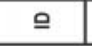 & - & $\sim$ & m & $\nabla$ & in & 0 & $n$ & $\infty$ \\
\hline
\end{tabular}




\begin{tabular}{|c|c|c|c|c|c|c|c|c|c|c|c|}
\hline 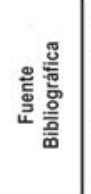 & 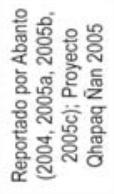 & 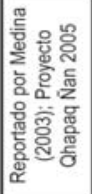 & 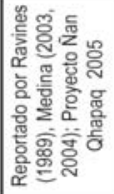 & 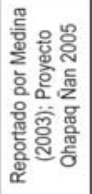 & 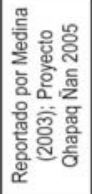 & 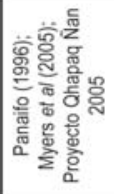 & 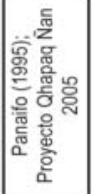 & 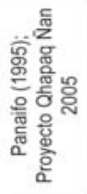 & 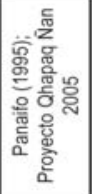 & 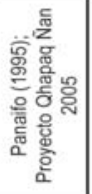 & 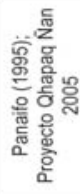 \\
\hline$\frac{\frac{\pi}{n}}{\underline{n}}$ & $\times$ & $\times$ & $\times$ & $\times$ & $\times$ & $\times$ & $\times$ & $\times$ & $\times$ & $\times$ & $\times$ \\
\hline 兽总 & $\times$ & $\times$ & $\times$ & $\times$ & $\times$ & $\times$ & $\times$ & $\times$ & $\times$ & $\times$ & $\times$ \\
\hline 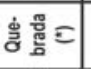 & $\times$ & 惡总 & $\times$ & $\times$ & $\times$ & $\times$ & $\times$ & $\times$ & $\times$ & $\times$ & $\times$ \\
\hline 荵 & & & & $\begin{array}{l}\text { 竎 } \\
\text { के }\end{array}$ & $\begin{array}{l}\text { 离 } \\
\text { 竧 }\end{array}$ & & & & & & \\
\hline 㝘 & 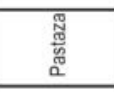 & 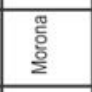 & 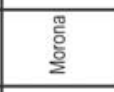 & 厂兽 & 厂兽 & 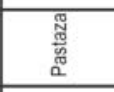 & 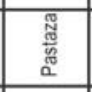 & 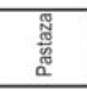 & 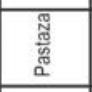 & 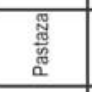 & 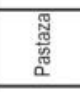 \\
\hline 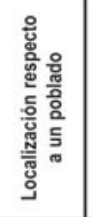 & 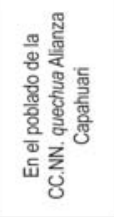 & 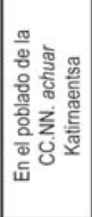 & 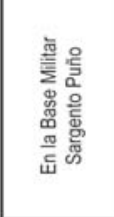 & 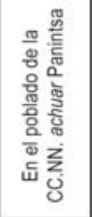 & 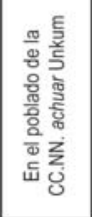 & 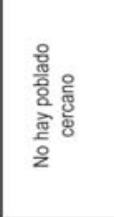 & 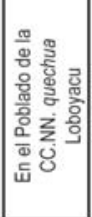 & 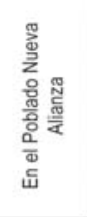 & 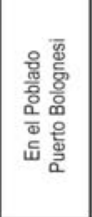 & 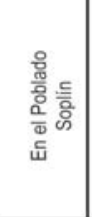 & 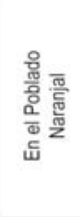 \\
\hline $\begin{array}{l}\text { 융 } \\
\circ \frac{0}{0} \\
\text { 응 }\end{array}$ & 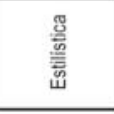 & 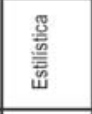 & 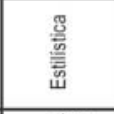 & $\begin{array}{l}\text { 哭 } \\
\text { 鲸 } \\
\text { 山ै }\end{array}$ & $\begin{array}{l}\text { 总 } \\
\text { 厗 } \\
\text { 崫 }\end{array}$ & 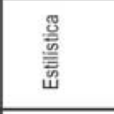 & 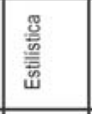 & 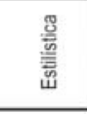 & $\begin{array}{l}\text { 哭 } \\
\text { 层 } \\
\text { W }\end{array}$ & 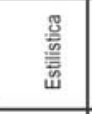 & 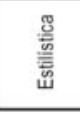 \\
\hline 题 & 灾 & 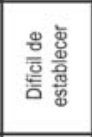 & 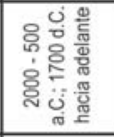 & 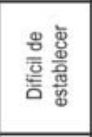 & 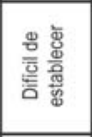 & 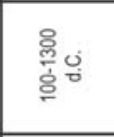 & 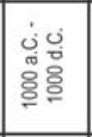 & 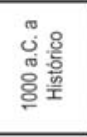 & 递 & 递 & 寅 \\
\hline 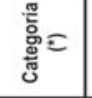 & 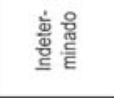 & 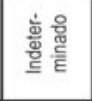 & 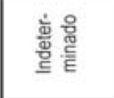 & $\begin{array}{l}\text { 离。윰 } \\
\text { 흘 } \\
\text { 들 }\end{array}$ & 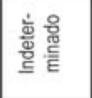 & $\begin{array}{l}\text { 혱유 } \\
\text { क्ष } \\
\text { 들 }\end{array}$ & 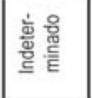 & 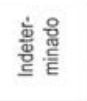 & 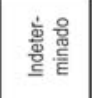 & 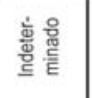 & 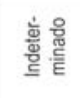 \\
\hline 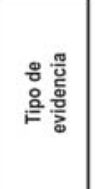 & 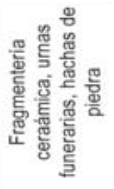 & 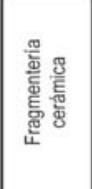 & 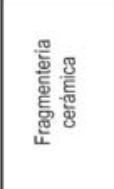 & 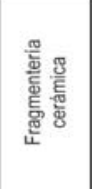 & 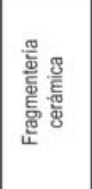 & 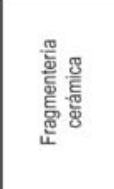 & 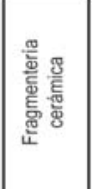 & 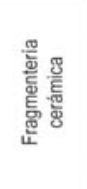 & 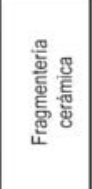 & 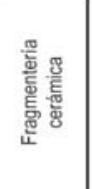 & 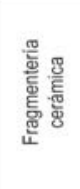 \\
\hline 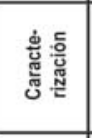 & 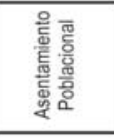 & 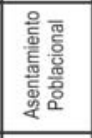 & 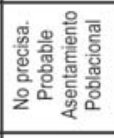 & 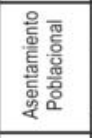 & 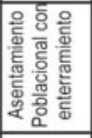 & 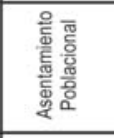 & 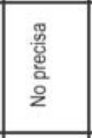 & $\begin{array}{l}\frac{\pi}{80} \\
\frac{0}{0} \\
\frac{0}{2}\end{array}$ & 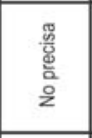 & 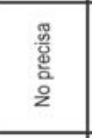 & 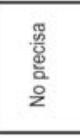 \\
\hline 욯 & 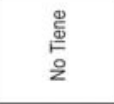 & 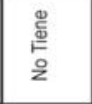 & 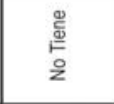 & 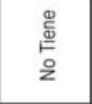 & $\begin{array}{l}\stackrel{\Phi}{\frac{\Phi}{E}} \\
\stackrel{\circ}{2}\end{array}$ & 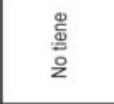 & 형 & $\overline{\bar{z}}$ & $\overline{\overrightarrow{\mathrm{D}}}$ & 嵩 & $\frac{\bar{\alpha}}{\frac{\bar{\alpha}}{2}}$ \\
\hline 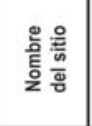 & 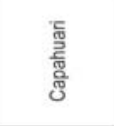 & 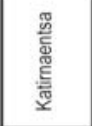 & 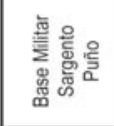 & 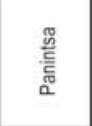 & 惡 & 읗윯 & 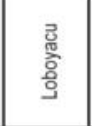 & 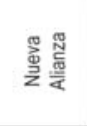 & 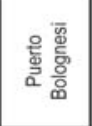 & 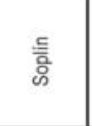 & 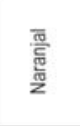 \\
\hline 으 & $\infty$ & 으 & $=$ & $\simeq$ & $\cong$ & \pm & 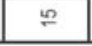 & 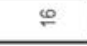 & $=$ & $\stackrel{\infty}{\leftarrow}$ & 우 \\
\hline
\end{tabular}




\begin{tabular}{|c|c|c|c|c|c|c|c|c|c|c|c|}
\hline 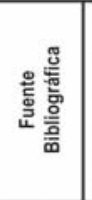 & 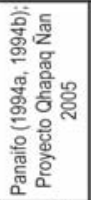 & 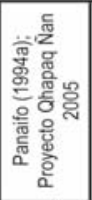 & 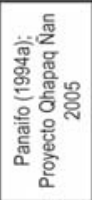 & 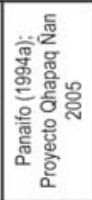 & 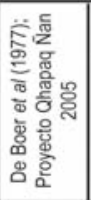 & 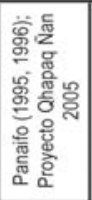 & 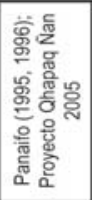 & 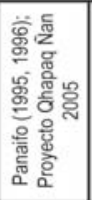 & 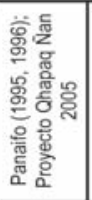 & 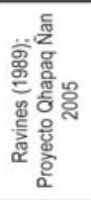 & 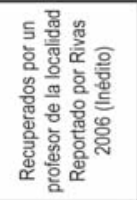 \\
\hline$\frac{\pi}{\underline{m}}$ & 등 & 들 & 䍃产 & 岳产 & $\times$ & $\times$ & $\times$ & $\times$ & $\times$ & $\times$ & $\times$ \\
\hline 察兽 & 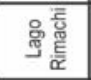 & 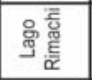 & 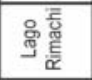 & 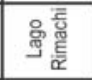 & $\times$ & $\times$ & $\times$ & $\times$ & $\times$ & $\times$ & $\times$ \\
\hline 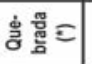 & $\times$ & $\times$ & $\times$ & $\times$ & $\times$ & $\times$ & $\times$ & $x$ & $\times$ & $\times$ & $\times$ \\
\hline 怘 & $\begin{array}{l}\overline{\overline{2}} \\
\text { 蹗 } \\
\end{array}$ & 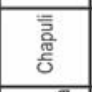 & 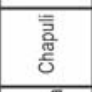 & 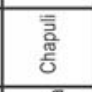 & 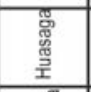 & $\begin{array}{l}\mathscr{8} \\
\text { 艿 } \\
\text { 至 } \\
\end{array}$ & $\begin{array}{l}\stackrel{8}{8} \\
\text { 若 } \\
\text { 至 } \\
\end{array}$ & $\begin{array}{l}\mathbb{8} \\
\text { 怘 } \\
\text { 至 } \\
\end{array}$ & $\begin{array}{l}\mathbb{8} \\
\mathbb{8} \\
\mathbb{m} \\
\text { 至 } \\
\end{array}$ & & $\times$ \\
\hline 亡্் & 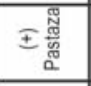 & 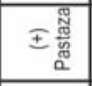 & 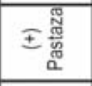 & 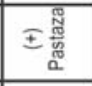 & 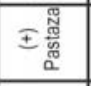 & 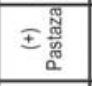 & 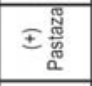 & 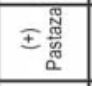 & 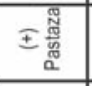 & 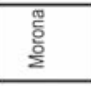 & 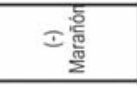 \\
\hline 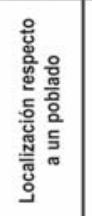 & 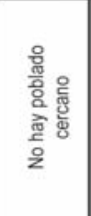 & 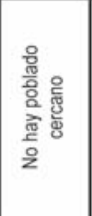 & 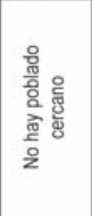 & 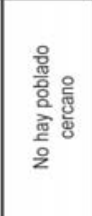 & 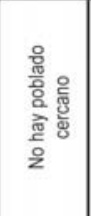 & 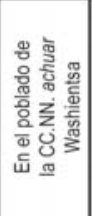 & 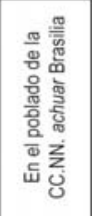 & 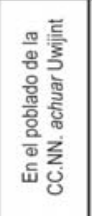 & 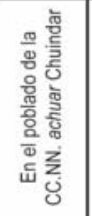 & 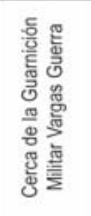 & 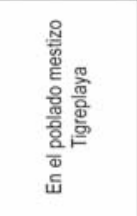 \\
\hline $\begin{array}{l}\text { 융 } \\
\text { 응 } \\
\text { 은 }\end{array}$ & 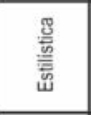 & 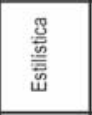 & 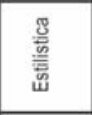 & 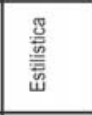 & 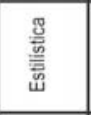 & $\begin{array}{l}\text { 总 } \\
\text { 誊 } \\
\text { w }\end{array}$ & 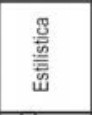 & 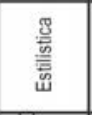 & 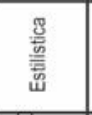 & $\begin{array}{l}\text { 搃 } \\
\text { 言 } \\
\text { w }\end{array}$ & 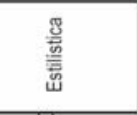 \\
\hline 苋 & ن. & 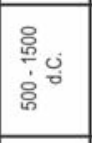 & 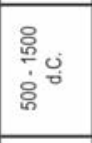 & 总 & . & 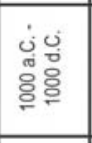 & 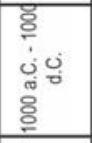 & 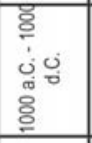 & 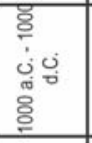 & 号. & 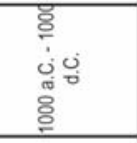 \\
\hline 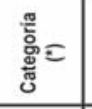 & 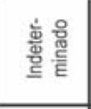 & 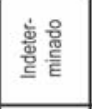 & 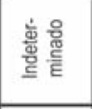 & 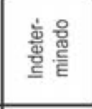 & 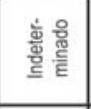 & 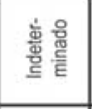 & 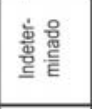 & 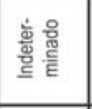 & 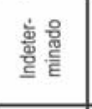 & 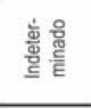 & 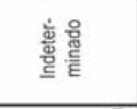 \\
\hline 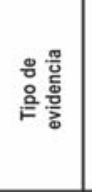 & 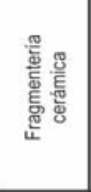 & 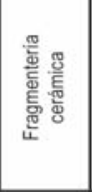 & 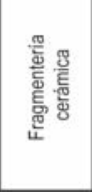 & 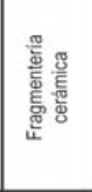 & 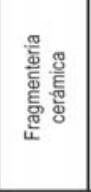 & 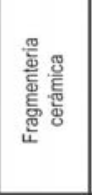 & 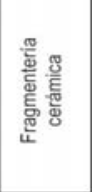 & 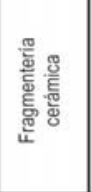 & 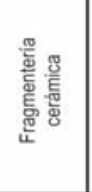 & 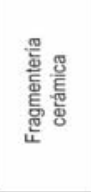 & 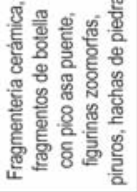 \\
\hline 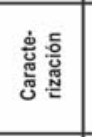 & $\begin{array}{l}\frac{\pi}{0} \\
\frac{0}{0} \\
2 \\
2\end{array}$ & $\begin{array}{l}\text { 总 } \\
\text { 总 } \\
\text { 2 }\end{array}$ & 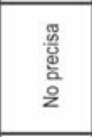 & $\begin{array}{l}\dddot{\pi} \\
\frac{\pi}{0} \\
\frac{0}{2} \\
2\end{array}$ & 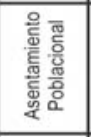 & 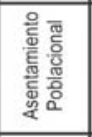 & 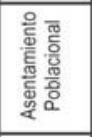 & 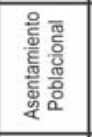 & 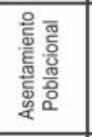 & $\begin{array}{l}\frac{w}{0} \\
\frac{w}{0} \\
\frac{0}{2} \\
\frac{0}{2}\end{array}$ & 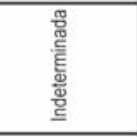 \\
\hline 음 & 产 & 旁 & $\frac{?}{4}$ & $\frac{y}{\frac{y}{x}}$ & $\begin{array}{l}\frac{\mathscr{\Phi}}{2} \\
\stackrel{2}{2}\end{array}$ & $\begin{array}{l}\text { Tे } \\
\text { 竞 } \\
\text { دે }\end{array}$ & 离 & $\overline{\bar{z}}$ & 咅 & $\begin{array}{l}\frac{9}{\mathrm{E}} \\
\stackrel{0}{\mathrm{~g}} \\
\mathrm{z}\end{array}$ & 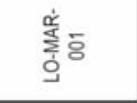 \\
\hline 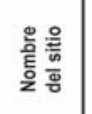 & 总 & 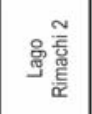 & 兽䓫 & 兽奠 & 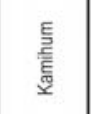 & 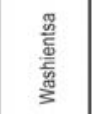 & 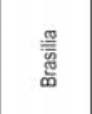 & 总福 & 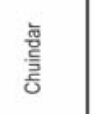 & 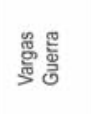 & 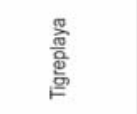 \\
\hline 으 & ㄱ. & $\bar{\sim}$ & $\approx$ & $\tilde{N}$ & $\mathbb{Z}$ & $\stackrel{2}{2}$ & $\stackrel{\sim}{ }$ & $\tilde{N}$ & $\stackrel{\sim}{\sim}$ & ని & প্ \\
\hline
\end{tabular}


del Pastaza (Quechua de la selva) en la cuenca media; y los candoshi (familia lingüística Candoshi), en la cuenca baja.

- De esta cultura arqueológica recién conocemos la forma y características de sus vasijas utilitarias. No tenemos reporte de la existencia de piruros, coladores, hachas de piedra o sellos, indicadores de presencia de textil, consumo de masato, agricultura de corte y quema, y ornamentos corporales, respectivamente. Sin embargo sí se tiene la evidencia del fragmento de posible mano de moler, lo que estaría indicando que tenían granos en su dieta alimenticia.

- Desconocemos la filiación étnica de este grupo, pero por las características cerámicas, sobre todo por el temperante (cuarzo y fragmentos líticos de composición diversa), formas de labios redondeados, bordes de cuencos convexos, bases convexas y cónicas, y decoración corrugada, parecen relacionarse de algún modo con las poblaciones de la cultura Huagramona, del río Pastaza.

- La presencia de cerámica del alfar 2 es posterior al grupo del alfar 1, y debe ser posterior a los años 1500 d.C.

\section{Subcuenca del Bajo Huasaga - Lago Anatico}

- En la subcuenca del Bajo Huasaga existen por lo menos tres ocupaciones humanas arqueológicas de diferentes épocas:

- La más tardía está representada por un grupo simple de vasijas con temperante de apacharama del alfar 2, y que deben ser posteriores a los años 1500 d.C.

- Le sigue una amplia y densa ocupación humana para los años 1000 d.C. hacia delante (periodo Intermedio Tardío: 1000 - 1500 d.C.) a la que estamos llamando cultura Anatico (para los habitantes del lago Anatico) y cultura Huasaga (para los habitantes del río Huasaga). Ellos produjeron la cerámica del alfar 1.

De esta cultura conocemos sus formas y características de sus vasijas utilitarias de cuencos y ollas, decoradas y no decoradas, como también de sus tinajas, que eran utilizadas para enterrar a sus muertos, y lo que parece más probable también para almacenar líquidos y cocinar sus alimentos. Algunos asentamientos poblacionales tenían sus enterramientos en el mismo poblado, pero no podemos afirmar en estos momentos si dichos enterramientos se hacían en el interior de las viviendas o fuera de ellas, o si destinaban un lugar especial para sus cementerios.

Este grupo se relaciona con la cultura Huagramona del Pastaza, por las fuertes semejanzas en las formas de los cuencos, ollas y tinajas (bordes convexos o 
divergentes, cuerpos convexos o globulares, y bases convexas o cónicas), así como las decoraciones plásticas y pintadas: triángulos impresos, trapecios impresos, círculos impresos, puntos impresos, líneas impresas, corrugados, incisiones formando triángulos combinado con círculos estampados y pintura roja, negra o blanco en la cara externa, además de incisiones diagonales opuestas formando diseños de rombos, triángulos impresos.

- La ocupación humana más antigua está testificada en los cinco sitios arqueológicos del bajo Huasaga, para los años 1000 a.C. (período Formativo Tardío) hacia adelante, y que se caracterizan por la presencia de figurinas humanas, sobre todo femeninas (de arcilla sólida), así como también por las botellas con pico y asa puente lateral (Fotos $\mathrm{N}^{\circ} 8$ y 9), también presentes en la cuenca del Morona (Fotos $\mathrm{N}^{\circ} 10$ y 11), que servían para contener agua y/o algunas pócimas medicinales (en este caso la botella con aplicación en forma de lombriz intestinal puede haber sido para guardar sustancias antihelmínticas). En estas predominan el temperante con abundante presencia de cuarzo y partículas de rocas de diversos tipos.

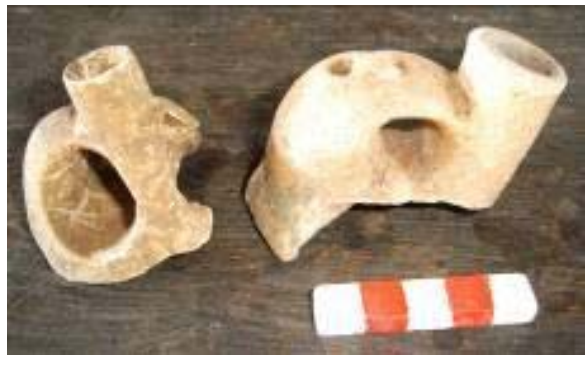

Foto 8.

Fragmentos de botella con pico y asa puente lateral. Sitio arqueológico Alianza Cristiana, Lago Anatico, río Huasaga. Mayo 2006. Foto: Santiago Rivas Panduro

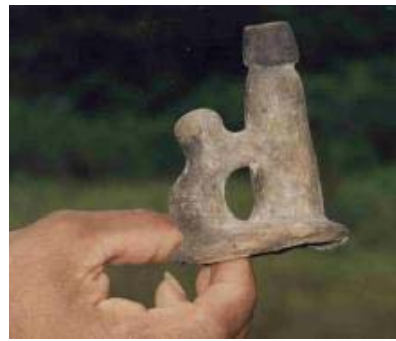

Foto 10.

Picos de botella del sitio Katirnaentsa, río Situche Mayo 2006. Foto: Ada Medina Mendoza

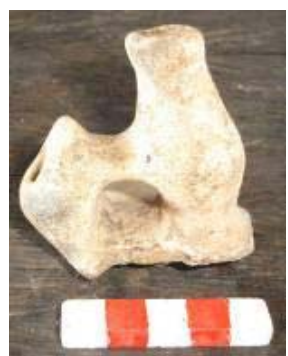

Foto 9.

Fragmento de botella con pico y asa puente lateral. Sitio arqueológico Alianza Cristiana, Lago Anatico, río Huasaga Mayo 2006. Foto: Santiago Rivas Panduro

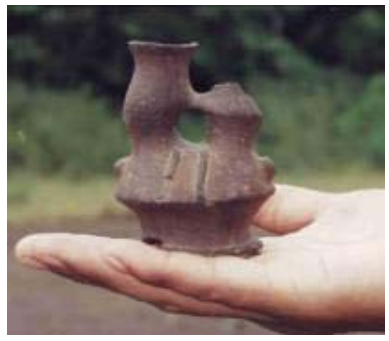

Foto 11.

Picos de botella del sitio Katirnaentsa, río Situche. Mayo 2006. Foto: Ada Medina Mendoza 
- También se ha reportado para este grupo piruros, coladores, hachas de piedra o sellos, indicadores de presencia de actividad textil, consumo de masato, agricultura de corte y quema, y ornamentos corporales, respectivamente.

- $\quad$ Es relevante la comparación ente los materiales de nuestros estudios con los de otras cuencas tributarias del bajo Marañón, y sobretodo con la costa ecuatoriana, porque de ella se tiene la cronología absoluta de las diversas ocupaciones humanas.

- Las culturas del período Formativo del Bajo Huasaga - Lago Anatico se relacionan con las culturas de la costa y sierra ecuatoriana como Valdivia (Formativo Temprano: 2000 a.C.) por el parecido de las figurinas femeninas (Evans et al, 1957; Estrada, 1958); Machalilla (Formativo Temprano: 1000 a.C.) por el parecido de las figurinas humanas y las hachas de piedra; Chorrera (Formativo Tardío: 1000 - 0 a.C.) por el parecido de fragmentos con los picos de botellas con asa puente (lateral), las hachas de piedra, sellos, piruros y coladores; y con varias culturas del periodo Desarrollo Regional (1 - 1000 d.C.) por el parecido de los piruros o torteros (Estrada, 1958, 1962).

- Respecto a las culturas amazónicas, básicamente las culturas del período Formativo del Bajo Huasaga - Lago Anatico, guardan relación con las culturas formativas como las de Chambira en el río homonimo, por la similitud de las figurinas femeninas y botellas con pico asa puente (Morales, 1992, 1998; Myers et al, 1999; Rivas, 2005b); las del río Huitoyacu, por el parecido de los picos de botellas y figurinas (Rivas, 2003b; Myers et al, 2005); las del río Corrientes por el parecido con las botellas con pico asa puente y figurinas femeninas (Ravines, 1981; Fung, 1981); y las del Ucayali por el parecido con las botellas con pico y asa puente (Lathap, 1970; Ravines, 1981).

\section{E. Cuenca del río Pastaza}

- $\quad$ Para el Pastaza, los dos asentamientos arqueológicos reportados en nuestras investigaciones nos muestran estar emparentados entre sí, por las amplias semejanzas en las formas, decoraciones y temperante de sus vasijas, como ya ha quedado ampliamente demostrado a lo largo de las descripciones e ilustraciones respectivas. A este grupo lo estamos denominando cultura Huagramona, cuya antigüedad relativa (estimada como la de las anteriores culturas y ocupaciones humanas) va por los años 1000 d.C. hacia delante.

- La peculiaridad de esta cultura, es que se dispone de documentos etnohistóricos que señalan que los miembros de la cultura Huagramona parece que fueron pertenecientes a la etnia pinche (extintos, como etnia por lo menos desde hace un siglo, ver testimonios líneas arriba), pues los pinche estuvieron asentados como reducción en lo que hoy es la CC.NN. Huagramona (sitio arqueológico Huagramona), desde los años 1600 hacia adelante (Santillana, 2004). 
- Lo que nosotros proponemos para designar la antigüedad de la cultura Huagramona, que corre de los años 1000 d.C., es en el hecho de que este grupo debe haber existido en la zona mucho antes de la formación de la reducción por parte de los misioneros (sino ¿de dónde vinieron los habitantes a quienes los redujeron?); y porque el temperante de cuarzo y partículas de rocas de diversos tipos está apareciendo en las poblaciones arqueológicas de esa época.

- La cultura Huagramona del Pastaza (o su influencia cultural evidenciada a partir de los elementos decorativos de sus vasijas), se extendió hacia otras cuencas, como la del Bajo Huasaga y el lago Anatico, a más o menos $46 \mathrm{~km}$ de distancia al SSO. Esto se desprende de la amplia distribución de los elementos decorativos de sus vasijas, sobre todo por las decoraciones con incisiones formando triángulos combinados con círculos estampados y pintura roja, negra o blanca en la cara externa (Abanto 2004, 2005a, 2005b, 2005c; Gonzales, 2005), representadas con abundancia en el sitio arqueológico Huagramona (el más extenso e importante del Pastaza hasta ahora conocido); estos motivos son incluso observados en el sitio denominado Valencia, en el río Corrientes (Fung, 1981: 111).

- Pero las decoraciones con incisiones formando triángulos con círculos estampados y pintura, así como los puntos impresos, líneas impresas y corrugados, del sitio Huagramona, también aparecen por la desembocadura del río Platanoyacu en el Corrientes (Ravines, 1981; Fung, 1981), a 84 km al Este. A su vez, las decoraciones corrugadas y aplicaciones en forma de zigzag, que aparecen en Huagramona, también se observan en los sitios arqueológicos del Bajo Utcubamba, tributario derecho del Medio Marañón (Shady, 1973), en los sitios de los ríos Huayabamba, tributario del Medio Huallaga (Ravines, 1981) y Cachiyacu, sub tributario del Bajo Huallaga (Rivas, 2001, 2003a), notándose pues una extensa conexión entre estas poblaciones arqueológicas.

\section{CONSIDERACIONES FINALES}

- $\quad$ Con el hallazgo y reporte de 56 sitios arqueológicos por el Proyecto de ZEE Pastaza y Morona, y otros 30 sitios arqueológicos más (Mapa $\mathrm{N}^{\circ} 1$ y Cuadro $\mathrm{N}^{\circ} 2$ ), identificados y registrados por diversos investigadores en el ámbito de nuestros estudios, queda demostrado su alto potencial arqueológico, el mismo que demanda profundizar las investigaciones, desarrollando proyectos arqueológicos con excavaciones en los sitios más relevantes (de primer orden), ya que coadyuvarán a resolver problemas e hipótesis sobre la antigüedad de los asentamientos (secuencia de la arqueología de la región Pastaza - Morona), relaciones con otros grupos humanos del pasado, uso y aprovechamiento de los recursos, y filiación cultural con los grupos indígenas que hoy también las habitan: wampis, shapra, candoshi, achuar, quechua. 
- Los sitios arqueológicos en estas cuencas, muestran que las antiguas ocupaciones humanas eran más densas y amplias que las de las actuales poblaciones amazónicas.

- Indudablemente, el lago Rimachi (el segundo lago más grande del Perú, después del Titicaca) tiene un rol importante en la vida social y económica de las poblaciones actuales. Asumimos que lo mismo debió acontecer en el pasado. En esta circunstancia, un reconocimiento sistemático del lago en su período de nivel más bajo de agua, sería una buena oportunidad para examinar este comportamiento, y así inventariar los sitios aflorantes y establecer su relación con los asentamientos hallados al interior de sus tributarios.

Bibliografía

ABANTO, J.

2004 Evaluación Arqueológica sin Excavaciones en el Lote 1-AB. Zonas: Carmen, Jíbaro N.O. y Tambo. 26 pp. Informe presentado al Instituto Nacional de Cultura. Lima, Perú.

2005 (a) Proyecto de Evaluación Arqueológica para la Delimitación de los Sitios: Alianza Topal y Capahuari, y Plan de Monitoreo Arqueológico para los Sectores Carmen y Jíbaro N.O. Lote 1-AB. Primera Parte: Informe de la Delimitación de los Sitios Alianza Topal y Capahuari. 55 pp. Informe presentado al Instituto Nacional de Cultura. Lima, Perú.

2005 (b) Proyecto de Evaluación Arqueológica para la Delimitación de los Sitios: Alianza Topal y Capahuari, y Plan de Monitoreo Arqueológico para los Sectores Carmen y Jíbaro N.O. Lote 1-AB. Segunda Parte: Informe del Plan de Monitoreo Arqueológico para el Programa de estudio y exploraciones de Sísmica 3D, en el Lote 1 AB, Sector: Carmen. 60 pp. Informe presentado al Instituto Nacional de Cultura. Lima, Perú. 
2005 (c) Proyecto de Evaluación Arqueológica para la Delimitación de los Sitios: Alianza Topal y Capahuari, y Plan de Monitoreo Arqueológico para los Sectores Carmen y Jíbaro N.O. Lote 1-AB. Informe de la Ficha Técnica, Memoria Descriptiva y Planos de Sitios Delimitados. 14 pp. Informe presentado al Instituto Nacional de Cultura. Lima, Perú.

\section{ALLEN, W. L.}

1968 A Ceramic Sequence from the Alto Pachitea, Perú. M.S. Doctoral dissertation, University of Illinois, Urbana. USA.

\section{ANCIETA-CALDERÓN, F.}

1987 «La várzea amazónica peruana: Algunos fundamentos ecológicos». En: Boletín de Lima, No 54, pp. 33-44. N 54. Lima, Perú.

\section{DE BOER, W., ROSS E., ROSS J. \& VEALE M.}

1977 "Two Ceramic collections from the Rio Huasaga, Northe, Peru: Their Places in the Pre-history on Upper Amazon. In: El Dorado, Vol. II, N², pp. 10-27. University of Northem Colorado. Greeley, Colorado. USA.

\section{ERM PERÚ S.A.}

2002 Estudio de Impacto Ambiental - Social en el área Noroeste del Lote 64.90 pp. Lima, Perú.

ESTRADA, E.

1958 Las Culturas Pre-Clásicas Formativas o Arcaicas del Ecuador. 113 pp. Museo Víctor Emilio Estrada. Guayaquil, Ecuador.

1962 Arqueología de Manabí Central. 211 pp. Museo Víctor Emilio Estrada. Guayaquil, Ecuador.

EVANS, C. \& MEGGERS, B.

1957 «Formative Period Cultures in the Guayas Basing, Coastal Ecuador». In: American Antiquity, Vol. XXII. USA.

FAURA, G. S.

1962 Los ríos de la Amazonía Peruana. 629 pp. Imprenta del Colegio Militar Leoncio Prado. Lima. Perú.

FUNG, R.

1981 «Notas y Comentarios Sobre el Sitio Arqueológico de Valencia en el Río Corrientes». En: Amazonía Peruana, Vol. IV, No 7, pp. 99-137. Lima, Perú. 


\section{GERHARD \& FAST R.}

1981 Introducción al Idioma Achuar. 144 pp. Ministerio de Educación. Instituto Lingüístico de Verano. Documento de Trabajo No 20. Pucallpa, Perú.

\section{GONZALES, C.}

2005 Proyecto Arqueológico de Emergencia en Puerto Alegría. Municipalidad Distrital de Morona (FONCODES). Provincia de Alto Amazonas, región Loreto. 207 pp. Informe presentado al Instituto Nacional de Cultural. Lima, Perú.

\section{HARRIS, J.}

1967 The ceramic sequence at Cushillococha. Ms. Master's Thesis, University of Illinois. Urbana. USA.

INADE

2000 Estudio de Macrozonificación Ecológica Económica del Área Fronteriza Amazónico Peruano. 536 pp. Iquitos, Perú.

2002 Estudio de Macrozonificación Ecológica Económica del Área Fronteriza Peruana entre los ríos Pastaza - Cordillera Campanquiz. 508 pp. Lima, Perú.

\section{INADE - ECORAE}

2001 Estudio de la Compatibilización Ecológica Económica de las áreas fronterizas, del Proyecto de Desarrollo Sostenible del Área Fronteriza Amazónica Peruano Ecuatoriano. 171 pp. Lima, Perú.

LATHRAP, D.

1970 The Upper Amazon. 256 pp. Praeger Publishers. New York.

\section{MEDINA, A.}

2003 Proyecto de Evaluación Arqueológica en el Área Noroeste del Lote 64. 237 pp. Informe presentado al Instituto Nacional de Cultura. Lima, Perú.

2004 Plan de Monitoreo Arqueológico del Proyecto de Perforación Exploratoria en el Área Noroeste del Lote 64. Locaciones Situche Norte 1x, Situche Central 1x y Campamento Base Sargento Puño. Provincia de Alto Amazonas, Departamento de Loreto. Primera Etapa. 331 pp. Informe presentado al Instituto Nacional de Cultura. Lima, Perú.

2005 Proyecto de Evaluación Arqueológica con Excavaciones en el Área Sujeta a Actividades Exploratorias del Lote 101 - Pastaza, Departamento de Loreto. 500 pp. Informe presentado al Instituto Nacional de Cultura. Lima, Perú.

MIASTA, J.

1979 El Alto Amazonas: arqueología de Jaén y San Ignacio, Perú. Seminario de Historia Rural Andina. Universidad Nacional Mayor de San Marcos. Lima, Perú 


\section{MORALES, D.}

1992 «Chambira: alfareros tempranos de la Amazonía peruana». En: Editor Duccio Bonavia, pp. 149-172. FOMCIENCIAS. Lima, Perú.

1998 "Chambira: una cultura de sabana árida en la Amazonía peruana». En: Investigaciones Sociales, Año 2, No 2, pp. 61-75. UNMSM. Lima, Perú.

2000 «Las Poblaciones Prehistóricas». En: Investigaciones Sociales, Año 4, N 6, pp. 71-92. UNMSM. Lima, Perú.

2002 Investigaciones Arqueológicas en el distrito de Tigre (provincia de Loreto) y Las Amazonas (provincia de Maynas). 40 pp. Informe presentado al Instituto Nacional de Cultura. Lima, Perú.

\section{MORÁN, E. F.}

1993 La Ecología Humana de los pueblos de la Amazonía. 325 pp. Fondo de Cultura Económica. México.

\section{MYERS, T.}

1972 «Sarayacu: archaeological investigations at the 19 th century franciscan misión in the Peruvian Montaña». En: Actas y Memorias XXXIX Congreso Internacional de Americanistas, pp. 25-37, Lima, 1970. Vol. 4. Lima, Perú.

1976 «Isolation and ceramic change: a case from the Ucayali River, Perú». In: Word Archaeology. Vol. V., pp. 170-186. London.

1981 «Hacia la Reconstrucción de los Patrones Pre-Históricos Comunales en la Hoya Amazónica». En: Amazonía Peruana, Vol. IV, N 7, pp. 31-63. Lima, Perú.

1988 «Visión de la Prehistoria de la Amazonía Superior». En: Seminario de Investigaciones Sociales en la Amazonía, pp. 37-87. Talleres Gráficos del CETA. Iquitos, Perú.

\section{MYERS, T. \& DEAN B.}

1999 «Cerámica Prehispánica del Río Chambira, Loreto». En: Amazonía Peruana, Tomo No 26, pp. 255-288. Lima, Perú.

\section{MYERS, T. \& RIVAS, S.}

2005 «Evidencias Arqueológicas en el Alto Amazonas. Explorando las cuencas de los ríos Aichiyacu y Morona». En: Unay Runa, No 7, pp. 83-121. Lima, Perú.

\section{PANAIFO, M.}

1994 (a) «Evaluación de Nuestra Arqueología Amazónica». En: Amazonía: en Busca de su Palabra (Coordinada por Joaquín García Sánchez), pp. 169-229. IIAP. Iquitos, Perú.

1994 (b) Informe sobre la Visita para Evaluar Presencia de Recursos Culturales en el Lote 4. Loreto. Manuscrito sin publicar. Lima, Perú. 